\title{
The Agency Costs of On-the-Job Search*
}

\author{
Daniel Herbold ${ }^{\dagger} \quad$ Heiner Schumacher ${ }^{\ddagger}$
}

Version: March 9, 2020

\begin{abstract}
This paper studies how workers' on-the-job search influences optimal incentives in organizations. We analyze a principal-agent model in which the agent multitasks between working for the principal and searching for other job opportunities. The agent partly uses on-the-job search to improve his bargaining position within the relationship. We show that the optimal contract may feature both excessive performance bonuses as well as efficiency wages. Both measures reduce the agent's search incentives, but do not completely eliminate rent-seeking under the optimal contract. On-the-job search therefore generates agency costs. The model suggests a new rational for excessive incentive pay and efficiency wages.
\end{abstract}

Keywords: Repeated Games, Multitasking, Efficiency Wages, On-the-Job Search

JEL Classification: C73, D83, M52

\footnotetext{
*We are grateful to Sushil Bikhchandani (the editor), an anonymous associate editor, two anonymous referees, Ricardo Alonso, Dan Barron, Mark Bernard, Oscar Contreras, Matthias Fahn, Daniel Ferreira, Guido Friebel, Susanne Goldlücke, Sergei Guriev, Florian Hett, Heiko Karle, Michael Kosfeld, Matthias Kräkel, Albert Ma, Jim Malcomson, Francesca Melillo, Mike Powell, Michael Raith, Luis Rayo, Klaus Schmidt, Dirk Sliwka, Patrick van Cayseele and seminar participants at Carlos III de Madrid, University of New South Wales, Ludwig-Maximilians University, CUNEF, HU Berlin, University of Utah, Vanderbilt University, Pompeu Fabra, London School of Economics, Goethe-University Frankfurt, University of Cologne, University of Trier, Gothenburg (EEA meetings), Düsseldorf (Verein für Socialpolitik), Aarhus (SMYE), Tübingen (COPE) and the 2015 Workshop on Relational Contracts in Munich for valuable comments and discussions. The usual disclaimer applies.

${ }^{\dagger}$ Goethe-University Frankfurt, Theodor-W.-Adorno-Platz 4, 60323 Frankfurt am Main, Germany. E-mail: da.herbold@gmail.com.

$¥$ Corresponding Author. KU Leuven, Department of Economics, Naamsestraat 69, 3000 Leuven, Belgium. E-mail: heiner.schumacher@kuleuven.be.
} 


\section{Introduction}

On-the-job search is a widespread practice in the labor market. Workers in all kinds of occupations and positions frequently look for alternative employment opportunities. Since the mid 1980s, many labor markets have experienced a steep increase in job-to-job transition rates (Stewart 2002). Fallick and Fleischman (2004) show that there are about twice as many workers who change employers than workers who move from unemployment to employment; on-the-job search explains employment-to-employment transitions just as well as off-the-job search explains transitions from non-employment to employment. ${ }^{1}$ Job-to-job transitions seem to be especially common in high-technology clusters such as the computer industry in Silicon Valley (Fallick et al. 2006) as well as among consulting and professional service companies.

However, searching for a new job can be very time-consuming, involving activities such as attending job training courses, screening job advertisements, writing applications, preparing for job interviews, as well as traveling and meeting human resource representatives or employment agencies. Mueller (2010) reports that employed job seekers devote more than 100 minutes to search activities during each day of their search. Arellano and Meghir (1992) find that on-the-job search has a negative impact on hours worked. Moreover, to appear attractive to other employers, job seekers may shift their attention away from productive, less visible tasks, towards tasks that are less productive but more easily observed by outsiders. Therefore, employers may be concerned that their employees' on-the-job search impairs organizational performance.

In this paper, we examine how on-the-job search affects the provision of incentives inside organizations. We consider a repeated principal-agent model in which the agent (he) faces a multitasking problem (Holmström and Milgrom 1991). He can work for the principal (she) or search for outside options. Performing one activity drives up the costs of the other activity. The principal-agent relationship creates economic gains through the agent's work on the project and his opportunity to find a more attractive outside option. This framework provides novel perspectives on a variety of contractual arrangements as well as on recent developments in the incentive contracts which are employed in practice.

Our first key observation is that on-the-job search has mixed blessings. A certain level of on-the-job search is socially valuable as it leads to a better worker-firm match with positive probability. The first-best level of on-the-job search is therefore positive. However, finding a more valuable match is not the agent's only benefit from search effort. By generating outside

\footnotetext{
${ }^{1}$ See also Pissarides and Wadsworth (1994), Stevenson (2008), and Ahn and Shao (2017) for empirical evidence on the importance of on-the-job search for labor market dynamics. Highly skilled employees may also search for opportunities to start-up their own business; see the literature on the transition from employment to self-employment, e.g., Elfenbein et al. (2010) or Carnahan et al. (2012).
} 
offers, the agent improves his bargaining position within the current relationship. Securing outside offers is valuable for the agent - even when they represent less productive matches since they help him to negotiate better terms with the principal. ${ }^{2}$ Yet, on-the-job search for such offers is socially wasteful, as it creates effort costs, but only leads to a redistribution of the joint surplus.

How does the agent's on-the-job search affect the optimal incentive contract? In the absence of on-the-job search, the principal would realize all gains from trade by paying the agent the full marginal returns of his efforts and extracting all rents through a low fixed-wage. This contract is no longer optimal once the agent engages in on-the-job search. Relative to the first-best, the agent would invest too much into search because of his rent-seeking motive. We show that the optimal incentive contract exhibits two features that reduce excessive search incentives. The first feature is an excessive bonus for high output that reduces search through the well-known static effort-substitution effect. Since the principal can keep the agent's expected payoff constant by adjusting the wage, increasing the bonus above full marginal returns results in first-order gains, but only second-order costs. Nevertheless, very large bonus payments are costly for the principal since she has to compensate the agent for the costs of excessive effort. Hence, the effectiveness of excessive bonuses to reduce search is limited.

The second feature of the optimal incentive contract is more subtle and stems from the dynamic nature of on-the-job search. If the principal always extracts all rents from the agent, the agent has substantial incentives to invest in search since even low-value offers improve his bargaining position. The principal can further curb search incentives by promising the agent a continuation payoff above the value of very unattractive outside options. This promise can be credible when the expected duration of the relationship is sufficiently long. Essentially, the principal then pays an efficiency wage to reduce rent-seeking through on-the-job search. Thus, the optimal incentive contract may exhibit both excessive bonus payments and efficiency wages. Both features reduce search incentives. However, since the principal cannot credibly promise the agent the entire value of the relationship, search incentives remain inefficiently high under the optimal contract. On-the-job search therefore creates agency costs.

Our paper offers a new perspective on the increase in the use of performance pay in many occupations. Since the 1980s, both the share of workers who receive some type of performance pay (piece rates, bonuses, or stock options), and the importance of performance pay relative to fixed wages, has increased significantly, especially for highly skilled workers (e.g., Lazear and Shaw 2007). This development contributed substantially to the rise in wage inequality. There are different explanations for the increase in the use of performance pay. First, the increase in

\footnotetext{
${ }^{2}$ Employers frequently match offers from competing firms to retain their best workers; see Barron et al. (2006) and Yamaguchi (2010).
} 
the returns to skill (due to technological changes) may induce firms to offer performance pay in order to attract talented workers. Lemieux et al. (2009) show that workers' total compensation is more closely related to their productive characteristics if they receive performance pay, which is consistent with the sorting hypothesis. Alternatively, steep increases in the use of performance pay may not reflect technological changes, but are more likely a result of poor corporate governance; see Bertrand and Mullainathan (2001). The prevalence of this view is also illustrated by the increase in compensation-related regulations in recent years. ${ }^{3}$

In this paper, we suggest an extension of the sorting hypothesis. Performance pay may be used to not only attract talented workers, but also to retain them. Many industries experience intense competition for talent in the labor market (Friebel and Giannetti 2009). Workers who face stronger competition for their services can generate better outside offers and thus may enjoy higher returns from on-the-job search. In order to distract workers from wasteful onthe-job search, firms optimally offer excessive performance pay to them.

Our model also offers a new rational for paying efficiency wages. Efficiency wage models describe mechanisms that imply a positive relationship between a worker's wage and his productivity. The most commonly used efficiency wage model in contract theory is that of Shapiro and Stiglitz (1984). In their framework, employers motivate their staff by paying wages above the market-clearing level and firing workers who are caught shirking. The equilibrium wage leads to involuntary unemployment so that losing a job is costly for workers. ${ }^{4}$ In our model, the rent that the agent receives does not reward him for good performance, but reduces his wasteful on-the-job search activities and thereby increases productivity. For this reason, the optimal incentive contract may combine efficiency wages with performance pay. This is in contrast to classic models (such as MacLeod and Malcomson 1998) in which firms offer to a worker either efficiency wages or bonus payments.

The remainder of the paper is organized as follows. In Section 2, we relate our contribution to the previous literature. Section 3 describes the model. In Section 4, we examine how on-thejob search changes the optimal incentive contract. In Section 5, we discuss several extensions of the baseline model. Section 6 concludes. All proofs are relegated to the Appendix.

\footnotetext{
${ }^{3}$ For example, in the European Union, the Capital Requirements Directive (CRD) imposes a bonus cap on the compensation of asset managers. Moreover, several European countries have passed laws capping the variable compensation of managers, while in the US, the Dodd-Frank Act also contains a set of compensation-related regulations.

${ }^{4}$ There exist several different mechanisms that generate a positive wage-productivity relationship. A high wage may be interpreted as a gift from the employer that the worker reciprocates by increasing his effort (Akerlof 1982). Alternatively, employers may offer high wages to lower turnover (Stiglitz 1974 and Salop 1979) or to increase the quality of their pool of applicants (e.g., Weiss 1980).
} 


\section{Related Literature}

Our paper contributes to various strands of the contract theory and labor economics literature.

Contract Design with On-the-Job Search. There are a few papers that study optimal contract design with moral hazard and on-the-job search. ${ }^{5}$ Moen and Rosen (2013) study a two period principal-agent model in which the agent invests in search to find a better match in the second period. The optimal contract in this setting distorts search incentives below the efficient level through deferred compensation. Board and Meyer-ter Vehn (2015) examine the labor market equilibrium when firms provide effort incentives through the threat of layoffs only (as in Shapiro and Stiglitz 1984) and workers are randomly matched to job offers. They show that this model generates dispersion in wages and productivity even if firms and workers are ex-ante identical. Tsuyuhara (2016) studies a labor market model in which firms can commit to increasing wage schedules, and workers search for specific job offers. He shows that in equilibrium firms offer increasing wage schedules to provide effort incentives and to retain workers; the latter motive then vanishes with job tenure. The key difference between our model and these papers is that, in ours, the agent faces a multitasking problem. The optimal incentive contract therefore exhibits properties that do not arise in these models. ${ }^{6}$

A number of papers analyze optimal contracts when agents choose their search effort endogenously and work effort within the organization is not subject to a moral hazard problem; see Mortensen (1978), Postel-Vinay and Robin (2004), and Lentz (2014). They show that rent-seeking on-the-job search can be reduced by back-loading the agent's compensation in long-term contracts. This solution is not available in our framework since the principal cannot commit to long-term contracts.

Relational Contracts. When performance measures are not verifiable to third parties or the agent's performance can only be assessed subjectively, parties may agree on relational contracts, i.e., contracts which rely on repeated-game incentives; see Bull (1987), MacLeod and Malcomson (1989), and Levin (2003). Within this literature, the model by Baker et al. (2002)

\footnotetext{
${ }^{5}$ There is a large literature that examines the impact of on-the-job search on aggregate economic outcomes. Pissarides (1994) studies search unemployment with on-the-job search; Burdett and Mortensen (1998) and Christensen et al. (2005) show that on-the-job search can generate wage and productivity dispersion among ex-ante homogeneous workers; Lentz (2010) analyzes aggregate sorting patterns in the labor market under on-the-job search and Lise (2013) studies how on-the-job search and precautionary savings shape earnings inequality.

${ }^{6}$ Another related paper is Englmaier et al. (2014) who study optimal contracts for "knowledge workers" in a static setting. The agent's effort not only increases the expected output, but also the value of the agent's outside option. As in our setting, the agent may leave the principal too early under the optimal contract. Hvide and Kristiansen (2012) study optimal incentive contracts when knowledge workers may steal ideas from firms that they generated through their work. In both models, there is no multitasking. Hence, the shape of the optimal contract in these models is quite different from that in ours.
} 
is related to ours in the sense that one party can invest in the alternative use value of its product, which would improve the bargaining position within the relationship. The authors examine how asset ownership changes the relational contract in this setting. A number of papers find non-trivial employment dynamics in stationary environments as we have in our model; see Chassang (2010), Halac (2012), and Li and Matouschek (2013). Fuchs (2007) considers a repeated principal-agent model in which only the principal observes the agent's output. The optimal contract in this setting is an efficiency wage contract that motivates the agent through the threat of dismissal. Fuchs (2007) therefore provides a micro-foundation for the efficiency wage model in Shapiro and Stiglitz (1984). Maestri (2012) complements the analysis in Fuchs (2007) by showing that an efficiency wage contract is inferior to a performance pay contract if the agent observes a signal that is sufficiently correlated with his output.

In our model, payoff promises are sustained through a relational contract. Moreover, we show that our main result also holds when the bonus is discretionary. Thus, we contribute to the relational contracts literature by demonstrating that the optimal relational contract may feature both excessive bonuses and efficiency wages when the agent engages in on-the-job search.

Multitasking. After the seminal paper by Holmström and Milgrom (1991), a large body of literature analyzed optimal incentive contracts when agents perform multiple tasks. The two most closely related papers in this literature are Schöttner (2008) and Benabou and Tirole (2016). Schöttner (2008) examines the optimal combination of explicit and relational contracts in a multitasking setup with infinitely many periods. The different tasks all contribute to the value of the principal's project, while the agent's outside option value is fixed. The optimal contract therefore features neither excessive bonuses nor efficiency wages. The model in Benabou and Tirole (2016) generates excessive bonuses in a static multitasking environment. Firms compete for talent and screen out highly skilled workers by offering performance incentives that exceed the second-best level. In our model, by contrast, the principal offers excessive bonuses to reduce the agent's search incentives. In addition, she may also pay efficiency wages to further reduce the agent's wasteful search activities.

\section{The Model}

Basic Framework. A principal interacts with an agent in periods $t=1,2, \ldots$. Both parties are risk-neutral and discount future payoffs by the discount factor $\delta \in(0,1)$. The relationship between principal and agent endures as long as the agent accepts the principal's contract offers. If he accepted all offers until period $t$, the principal offers a contract $\left(w_{t}, b_{t}\right)$, where $w_{t}$ is a fixed wage and $b_{t}$ is an output-based bonus. Both components are enforceable. We assume that the 
principal's human capital is needed for the project so that she cannot sell her complete business to the agent in the first period. ${ }^{7}$

Denote by $d_{t} \in\{0,1\}$ the agent's participation decision in period $t$. If he rejects the contract $\left(d_{t}=0\right)$, the agent gets the outside option value $r_{t}$ in period $t$ and the same value in all subsequent periods; in all periods $\tau \geq t$, the principal then earns zero and we have $d_{\tau}=0$. If he accepts the contract $\left(d_{t}=1\right)$, he exerts work effort $e_{t} \in[0, \bar{e}]$ and search effort $s_{t} \in[0, \bar{s}]$ at cost $c\left(e_{t}, s_{t}\right)$. The cost function is strictly convex in both arguments, $c_{e}\left(e_{t}, s_{t}\right)>0$ for $e_{t}>0$, $c_{s}\left(e_{t}, s_{t}\right)>0$ for $s_{t}>0, c_{e e}(\cdot)>0, c_{s s}(\cdot)>0 ;^{8}$ marginal effort costs at no effort are zero, $c_{e}\left(0, s_{t}\right)=c_{s}\left(e_{t}, 0\right)=0$; and cross-derivatives are positive, $c_{s e}(\cdot)=c_{e s}(\cdot)>0$, when $e_{t}>0$ and $s_{t}>0$, as well as $c_{e e}(\cdot) c_{s s}(\cdot)-c_{e s}(\cdot)^{2}>0$.

The agent's work and search effort choices are unobservable to the principal. Work effort generates output $y_{t} \in\{\underline{y}, \bar{y}\}$ with $\underline{y}<\bar{y}$. We denote $\Delta y=\bar{y}-\underline{y}$. When the agent exerts effort $e_{t}$, the probability of high output $\left(y_{t}=\bar{y}\right)$ is given by $f\left(e_{t}\right)$, where $f$ is weakly concave, $f^{\prime}(\cdot)>0$, $f^{\prime \prime}(\cdot) \leq 0, f(0)=0$, and $f(\bar{e}) \leq 1$. The output is publicly observable and verifiable to third parties. ${ }^{9}$ Search effort $s_{t}$ determines the probability $p\left(s_{t}\right)$ with which the agent finds an outside option in the next period. If he does not find an outside option in period $t$, his outside option value in this period is $r_{t}=0$. If he finds an outside option, his outside option value $r_{t}$ is drawn randomly according to the distribution function $G$. We assume that $G$ has full support on $(0, \infty)$, a continuous density function $g$ with $g(0)=0$, and finite mean $\mathbb{E}_{G}\left[r_{t}\right]<\infty$. The function $p$ is linear ${ }^{10}$ and has $p(\bar{s}) \leq 1$. For the first period, we assume that $r_{1}=0$.

The period- $t$ payoffs after accepting contract $\left(w_{t}, b_{t}\right)$ are as follows. If the agent chooses effort $\left(e_{t}, s_{t}\right)$, then with probability $f\left(e_{t}\right)$ the output is high. In this case, the agent's period payoff is $u_{t}=w_{t}+b_{t}-c\left(e_{t}, s_{t}\right)$, while the principal's payoff is $v_{t}=\bar{y}-w_{t}-b_{t}$; with the reverse probability, the output is low and the agent's period payoff is $u_{t}=w_{t}-c\left(e_{t}, s_{t}\right)$, while the principal's payoff is $v_{t}=y-w_{t}$. The agent is not protected by limited liability, so $w_{t}+b_{t}$ can be negative. In each period $t$, the principal observes $r_{t}$ and can tailor the contract to it. There is free disposal. The agent can reduce the value of his outside option to any value in $\left[0, r_{t}\right]$. Thus, in equilibrium, the agent's payoff cannot decrease in $r_{t}$. Figure 1 shows the sequence of events in period $t$ when the agent has accepted the principal's offers until this period.

Before we define strategies and equilibrium in our framework, a discussion of the outside option value $r_{t}$ is in order. This value captures the agent's expected continuation value if she

\footnotetext{
${ }^{7}$ For example, she may possess valuable but non-transferable client relationships. Alternatively, the principal may be doing some other necessary work or having some expertise which is not explicitly modeled, but is essential for the productiveness of the relationship.

${ }^{8}$ We use $c_{e}$ and $c_{s}$ to denote the partial derivative with respect to the first and second variable, respectively.

${ }^{9}$ In Subsection 5.1, we drop the assumption of verifiable output.

${ }^{10}$ This assumption is not essential for our results, but it simplifies their exposition substantially. Note that we have curvature in the effectiveness of search effort through the cost function.
} 
does not accept the principal's offer in period $t$. The assumption that there is no correlation between outside option values of different periods makes the model tractable. It is satisfied if $r_{t}$ captures the value of a vacancy offered to the agent in period $t$ that would be filled with somebody else after period $t$ if the agent rejects it. The exact value of $r_{t}$ then may reflect the relative bargaining power of the potential new employer (e.g., if she derives high value from the agent's service, her bargaining power is relatively low). Alternatively, $r_{t}$ may reflect the agent's payoff from becoming self-employed, using an idea encountered through employment. As time passes, market conditions change or the principal may start to use the agent's idea so that the opportunity is gone in period $t+1$.

\begin{tabular}{lllll}
$\perp$ & \multicolumn{1}{c}{$\perp$} & \multicolumn{1}{c}{$\perp$} & $\perp$ \\
\hline outside option & principal makes & agent accepts & agent chooses & outcome $y_{t}$ \\
value $r_{t}$ & contract offer & or rejects the & effort $\left(e_{t}, s_{t}\right)$ & realizes and \\
realizes & $\left(w_{t}, b_{t}\right)$ & principal's & & transfers \\
& & contract & & are made
\end{tabular}

Figure 1: Sequence of events in period $t$

Strategies and Equilibrium. Denote the set of publicly observable outcomes in period $t$ by $\varphi_{t}=\left(r_{t}, w_{t}, b_{t}, y_{t}, d_{t}\right)$. The history of play up to period $t$ is denoted by $h_{t}^{0}=\left(\varphi_{1}, \ldots, \varphi_{t-1}, r_{t}\right)$. Let $H_{t}^{0}$ be the set of such histories up to period $t$ and $H^{0}=\bigcup_{t \geq 0} H_{t}^{0}$ the set of all finite histories. The principal's strategy $\sigma_{P}$ maps the histories in $H^{0}$ into contract offers,

$$
\sigma_{P}: H^{0} \rightarrow \mathbb{R} \times \mathbb{R}
$$

The agent chooses his action upon observing the contract offer. Denote the history of play up to the point when the agent chooses his action in period $t$ by $h_{t}^{1}=\left(\varphi_{1}, \ldots, \varphi_{t-1}, r_{t}, w_{t}, b_{t}\right)$. Let $H_{t}^{1}$ be the set of such histories up to period $t$ and $H^{1}=\bigcup_{t \geq 0} H_{t}^{1}$. The agent's strategy $\sigma_{A}$ maps the histories in $H^{1}$ into a participation decision and effort choices,

$$
\sigma_{A}: H^{1} \rightarrow\{0,1\} \times[0, \bar{e}] \times[0, \bar{s}]
$$

Let the strategies $\sigma_{P}$ and $\sigma_{A}$ be given. In period $t$, the principal's normalized continuation value after history $h_{t}^{0}$ then equals

$$
V_{t}\left(h_{t}^{0}, \sigma_{P}, \sigma_{A}\right)=(1-\delta) \mathbb{E}\left[\sum_{\tau=1}^{\infty} \delta^{\tau} d_{t+\tau}\left(y_{t+\tau}-W_{t+\tau}\right) \mid h_{t}^{0}, \sigma_{P}, \sigma_{A}\right],
$$


where $W_{\tau}$ is the principal's payment to the agent in period $\tau$. The agent's normalized continuation value after history $h_{t}^{1}$ is given by

$$
U_{t}\left(h_{t}^{1}, \sigma_{P}, \sigma_{A}\right)=(1-\delta) \mathbb{E}\left[\sum_{\tau=1}^{\infty} \delta^{\tau}\left[d_{t+\tau}\left(W_{t+\tau}-c\left(e_{t}, s_{t}\right)\right)+\left(1-d_{t+\tau}\right) r_{\tilde{t}}\right] \mid h_{t}^{1}, \sigma_{P}, \sigma_{A}\right],
$$

where $\tilde{t}$ is the period in which (according to $h_{t}^{1}$ ) the agent rejected the principal's contract offer. A perfect public equilibrium is a strategy profile $\sigma=\left(\sigma_{P}, \sigma_{A}\right)$ such that (i) for any $h_{t}^{0} \in H^{0}$ and any alternative principal strategy $\hat{\sigma}_{P}$ we have $V_{t}\left(h_{t}^{0}, \sigma_{P}, \sigma_{A}\right) \geq V_{t}\left(h_{t}^{0}, \hat{\sigma}_{P}, \sigma_{A}\right)$, and (ii) for any $h_{t}^{1} \in H^{1}$ and any alternative agent strategy $\hat{\sigma}_{A}$ we have $U_{t}\left(h_{t}^{1}, \sigma_{P}, \sigma_{A}\right) \geq U_{t}\left(h_{t}^{1}, \sigma_{P}, \hat{\sigma}_{A}\right)$. Since the principal makes the contract offers, we are interested in the equilibrium that maximizes her payoff. We will therefore call an equilibrium $\sigma^{*}=\left(\sigma_{P}^{*}, \sigma_{A}^{*}\right)$ that maximizes $V_{0}\left(h_{1}^{0}, \sigma_{P}^{*}, \sigma_{A}^{*}\right)$ an "optimal incentive contract." ${ }^{11}$ As usual in repeated games, there are multiple equilibria, so an optimal incentive contract is typically not unique.

\section{The Optimal Incentive Contract}

\subsection{The Two Period Model}

As a benchmark, we first study the optimal incentive contract when principal and agent interact in only two periods $t=1,2$. This simple case illustrates important intuitions that will also be relevant for the infinite period model. We then can identify how repeated-game incentives affect the optimal incentive contract.

We can conveniently solve for the optimal incentive contract by using backward-induction. Consider period 2 and suppose that the agent has accepted the principal's offer in this period. Clearly, the agent will not invest into search, so that we have $s_{2}=0$. If the principal offered $\left(w_{2}, b_{2}\right)$ and the agent exerts work effort $e_{2}$, the principal's expected period-2 payoff equals $\underline{y}-w_{2}+f\left(e_{2}\right)\left(\Delta y-b_{2}\right)$, and the agent's expected period-2 payoff is $w_{2}+f\left(e_{2}\right) b_{2}-c\left(e_{2}, 0\right)$. The principal optimally implements the first-best level of work effort $e^{*}$ by paying the agent full marginal returns, $b_{2}=\Delta y$, and by extracting all rents through the fixed-wage $w_{2}$. The agent's expected payoff then equals her outside option value $r_{2}$. Denote by $Q_{2}^{*}$ the joint surplus in period 2 when the agent exerts work-effort $e^{*}$ (throughout the paper, we use the term "joint surplus" only for periods in which the agent works for the principal). It is given by

$$
Q_{2}^{*}=\underline{y}+f\left(e^{*}\right) \Delta y-c\left(e^{*}, 0\right) \text {. }
$$

\footnotetext{
${ }^{11}$ Throughout the paper, when we describe features of the optimal incentive contract, we refer to features that it has "almost always" (i.e., for convenience, we do not use the term "almost always").
} 
Since this is the maximal value of the relationship, $Q_{2}^{*}$ equals the first-best level of joint surplus in period 2, $Q_{2}^{*}=Q_{2}^{f b}$. Under the optimal incentive contract, the agent accepts the principal's offer if $r_{2} \leq Q_{2}^{*}$, and chooses the outside option if $r_{2}>Q_{2}^{*}$.

Next, consider period 1. Recall that the agent's outside option value in this period is $r_{1}=0$. If the principal offers $\left(w_{1}, b_{1}\right)$ to him, and he exerts work and search efforts $\left(e_{1}, s_{1}\right)$, his total expected payoff equals

$$
U_{1}=w_{1}+f\left(e_{1}\right) b_{1}-c\left(e_{1}, s_{1}\right)+\delta p\left(s_{1}\right) \mathbb{E}_{G}\left[r_{2}\right]
$$

Note that the agent earns two types of payoffs from working for the principal: The expected period-1 payoff $w_{1}+f\left(e_{1}\right) b_{1}-c\left(e_{1}, s_{1}\right)$, and the expected payoff from finding a better outside option in period $2, \delta p\left(s_{1}\right) \mathbb{E}_{G}\left[r_{2}\right]$. The optimal level of work and search efforts in period 1 are implicitly defined by the first-order conditions

$$
\begin{gathered}
f^{\prime}\left(e_{1}\right) b_{1}=c_{e}\left(e_{1}, s_{1}\right), \\
\delta p^{\prime}\left(s_{1}\right) \mathbb{E}_{G}\left[r_{2}\right]=c_{s}\left(e_{1}, s_{1}\right) .
\end{gathered}
$$

They imply that the agent's work effort $e_{1}$ strictly increases in the bonus $b_{1}$, while his search effort strictly decreases in $b_{1} \cdot{ }^{12}$ To derive the optimal bonus, consider the principal's expected payoff in period 1 ,

$$
V_{1}=\underline{y}-w_{1}+f\left(e_{1}\right)\left(\Delta y-b_{1}\right)+\delta\left(1-p\left(s_{1}\right)\right) Q_{2}^{*}+\delta p\left(s_{1}\right) G\left(Q_{2}^{*}\right)\left(Q_{2}^{*}-\mathbb{E}_{G}\left[r_{2} \mid r_{2} \leq Q_{2}^{*}\right]\right) .
$$

For any given bonus $b_{1}$, the principal optimally sets the wage $w_{1}$ so that all rents are extracted from the agent and we have $U_{1}=0$. Substituting this wage into equation (9) yields us

$$
\begin{aligned}
V_{1}=\underline{y} & +f\left(e_{1}\right) \Delta y-c\left(e_{1}, s_{1}\right) \\
& \left.+\delta\left(1-p\left(s_{1}\right)\right) Q_{2}^{*}+\delta p\left(s_{1}\right) G\left(Q_{2}^{*}\right) Q_{2}^{*}+\delta p\left(s_{1}\right)\left(1-G\left(Q_{2}^{*}\right)\right) \mathbb{E}_{G}\left[r_{2} \mid r_{2}>Q_{2}^{*}\right]\right) .
\end{aligned}
$$

Ignore for a moment the costs of search. Observe that the principal benefits from the agent's search as it increases the chance that he finds an outside option that is more valuable than the continuation of the relationship in period 2. This additional value depends on the conditional expected value $\left.\mathbb{E}_{G}\left[r_{2} \mid r_{2}>Q_{2}^{*}\right]\right)$. The principal extracts these gains through the fixed wage.

\footnotetext{
${ }^{12}$ We get $\frac{d e_{1}}{d b_{1}}>0$ and $\frac{d s_{1}}{d b_{1}}<0$ from implicit differentiation on (7) and (8); these terms are identical to those that we derive for the infinite period model, see the Appendix.
} 
Finally, to characterize the optimal bonus $b_{1}$, we get from (10) the first-order condition

$$
\begin{aligned}
\frac{\partial V_{1}}{\partial b_{1}}= & \frac{d e_{1}}{d b_{1}}\left[f^{\prime}\left(e_{1}\right) \Delta y-c_{e}\left(e_{1}, s_{1}\right)\right] \\
& +\frac{d s_{1}}{d b_{1}}\left[\delta p^{\prime}\left(s_{1}\right)\left(1-G\left(Q_{2}^{*}\right)\right)\left(\mathbb{E}_{G}\left[r_{2} \mid r_{2}>Q_{2}^{*}\right]-Q_{2}^{*}\right)-c_{s}\left(e_{1}, s_{1}\right)\right]=0
\end{aligned}
$$

Recall that work effort increases in the bonus, $\frac{d e_{1}}{d b_{1}}>0$, while search effort decreases in the bonus, $\frac{d s_{1}}{d b_{1}}<0$. We evaluate this first-order condition at $b_{1}=\Delta y$. Consider the expression in the squared brackets in the first line of (11). By the agent's first-order condition in (7), the agent chooses the optimal work effort $e_{1}$ for any given search effort $s_{1}$ when $b_{1}=\Delta y$. Hence, the first line equals zero at $b_{1}=\Delta y$. Next, consider the the expression in the large squared brackets in the second line of (11). Note from the agent's first-order condition in (8) that this expression must be strictly negative. ${ }^{13}$ Intuitively, this is the case since the agent searches "too much" from the principal's perspective. As discussed above, the principal benefits from search that is motivated by finding outside options that exceed the joint surplus in the second period $Q_{2}^{*}$. However, since the agent benefits from all positive outside option values, even those below $Q_{2}^{*}$, the agent invests more than the first-best level into search. Thus, the second line of (11) is strictly positive at $b_{1}=\Delta y$. In total, we have that $\frac{\partial V_{1}}{\partial b_{1}}$ is strictly positive at $b_{1}=\Delta y$. Therefore, the optimal bonus in period 1 exceeds $\Delta y$. Denote by $b_{1}^{*}$ an optimal bonus in period 1 , and by $e_{1}^{*}, s_{1}^{*}$ the corresponding levels of work and search effort, respectively. The joint surplus in period $1, Q_{1}^{*}$, is then given by $V_{1}$ in equation (10) when we insert $e_{1}=e_{1}^{*}$ and $s_{1}=s_{1}^{*}$.

The principal will offer an excessive bonus to partially curb rent-seeking through search by the agent. Nevertheless, for any given bonus, the agent will invest too much into search, so that the joint surplus in period 1 is below the first-best level, $Q_{1}^{*}<Q_{1}^{f b}$. Thus, the agency costs of job search are strictly positive. We summarize our results.

Proposition 1. Consider the two period model. The optimal incentive contract has the following properties. The joint surplus is maximized in the second period, $Q_{2}^{*}=Q_{2}^{f b}$, but not in the first period $Q_{1}^{*}<Q_{1}^{f b}$. The bonus is excessive in the first period, $b_{1}>\Delta y$.

The lack of commitment power on the side of the principal keeps the joint surplus away from the first-best level. The principal would gain if she could credibly promise to leave the joint surplus in period 2 to the agent. Search would then only be motivated by outside option values above $Q_{2}^{*}$ and hence be efficient. The principal could then extract all gains in period 1 . However, such a promise is not credible in the current setting as the interaction ends in period 2. As we discuss next, this problem is relaxed when there are infinitely many periods.

\footnotetext{
${ }^{13}$ To see this, we use $\mathbb{E}_{G}\left[r_{2}\right]=G\left(Q_{2}^{*}\right) \mathbb{E}_{G}\left[r_{2} \mid r_{2} \leq Q_{2}^{*}\right]+\left(1-G\left(Q_{2}^{*}\right)\right) \mathbb{E}_{G}\left[r_{2} \mid r_{2}>Q_{2}^{*}\right]$.
} 


\subsection{The Infinite Period Model - Preliminaries}

We first simplify the analysis of the infinite period model by restricting attention to equilibria in which the output $y_{t}$ affects the principal's and the agent's payoff only in period $t$, but not in periods $\tau>t$. This separation result follows from risk-neutrality. Any variation in expected future payments that implements a certain level of work effort $e_{t}$ and search effort $s_{t}$ can be generated through the proper choice of the bonus $b_{t}$. This simplifies the analysis substantially.

Lemma 1. Consider an equilibrium $\sigma$ in which the principal implements work effort $e_{t}^{*}$ and search effort $s_{t}^{*}$ after some history $h_{t}^{0}$ through a variation in payments after period $t$. Then there exists an equilibrium $\hat{\sigma}$ that is payoff equivalent and in which the principal implements $e_{t}^{*}, s_{t}^{*}$ after history $h_{t}^{0}$ by conditioning only the agent's payoff in period ton $y_{t}$.

With this result we can focus, without loss of generality, on equilibria in which the agent's total expected utility $U_{t}$ only depends on his outside option value $r_{t}$. We abuse notation and from now on denote by $U_{t}\left(r_{t}\right)$ the agent's total expected payoff in period $t$ in such an equilibrium as a function of his outside option value $r_{t}$. Let $V_{t}\left(r_{t}\right)$ be corresponding payoff for the principal. Given that the agent works for the principal in period $t$, he chooses work and search effort to maximize

$$
(1-\delta)\left(w_{t}+f\left(e_{t}\right) b_{t}-c\left(e_{t}, s_{t}\right)\right)+\delta\left(1-p\left(s_{t}\right)\right) U_{t+1}(0)+\delta p\left(s_{t}\right) \mathbb{E}_{G}\left[U_{t+1}\left(r_{t+1}\right)\right]
$$

Thus, the agent influences his continuation value only through his search effort. Differentiating this expression with respect to work and search effort yields two first-order conditions that characterize the agent's equilibrium actions: ${ }^{14}$

$$
\begin{gathered}
f^{\prime}\left(e_{t}\right) b_{t}=c_{e}\left(e_{t}, s_{t}\right), \\
\frac{\delta}{1-\delta} p^{\prime}\left(s_{t}\right)\left(\mathbb{E}_{G}\left[U_{t+1}\left(r_{t+1}\right)\right]-U_{t+1}(0)\right)=c_{s}\left(e_{t}, s_{t}\right) .
\end{gathered}
$$

Denote by $Q_{t}\left(r_{t}\right)=V_{t}\left(r_{t}\right)+U_{t}\left(r_{t}\right)$ the joint surplus in period $t$ if the agent works for the principal in this period and his outside option value is $r_{t}$. The joint surplus consists of two parts: the surplus from working in the principal's project and the (expected) surplus from accepting the outside option in the future. Suppose that in all periods $t$ the agent chooses work effort $e_{t}$, search effort $s_{t}$, and the participation decision $d_{t}$ so as to maximize the joint surplus. Note that the agent's decision problem is the same in each period in which he accepts the principal's offer. Therefore, there exists a unique value $Q^{f b}$ so that the maximal joint surplus in a given

\footnotetext{
${ }^{14}$ Throughout, we assume that the marginal costs of work and search effort rise quickly enough so that the agent's choices are given by interior solutions.
} 
period $t$ equals $Q^{f b}$ when $d_{t}=1$; there are unique levels of work and search effort, $e^{f b}$ and $s^{f b}$, so that the agent maximizes the joint surplus in period $t, Q_{t}=Q^{f b}$, if in all periods $\tau \geq t$ he chooses work effort $e_{\tau}=e^{f b}$, search effort $s_{\tau}=s^{f b}$, and $d_{\tau}=1$ if and only if $r_{\tau} \leq Q^{f b}$.

\subsection{The Infinite Period Model - Main Results}

We examine the optimal incentive contract in the infinite period model. By Lemma 1, we can focus on contracts in which the wage $w_{t}$ and bonus $b_{t}$ only depend on the current outside option value $r_{t}$. Thus, we can denote an optimal sequence of contract offers on the equilibrium path by $\left\{\left(w_{t}^{*}\left(r_{t}\right), b_{t}^{*}\left(r_{t}\right)\right)\right\}_{t=1}^{\infty}$. Let $Q_{t}^{*}\left(r_{t}\right)$ be the joint surplus created under an optimal incentive contract at date $t$ when $d_{t}=1$ and the outside option value is $r_{t}$. Our first main result is as follows:

Proposition 2. An optimal incentive contract has the following properties. The joint surplus is stationary and independent of the outside option, $Q_{t}^{*}\left(r_{t}\right)=Q^{*}$. In all periods $t$ in which the agent works for the principal, the joint surplus is not maximized, $Q^{*}<Q^{f b}$, and the bonus is excessive, $b_{t}^{*}\left(r_{t}\right)>\Delta y$.

The result shows that the optimal incentive contract implements an inefficient allocation. As in the two period model, the problem is that the agent's search incentives in any equilibrium are too large. If the outside option value is (weakly) smaller than the joint surplus, $r_{t} \leq Q^{*}$, the principal offers a contract that at least matches the agent's outside option, and the agent continues to work for the principal. Therefore, the agent may benefit from getting an outside offer even though he will not accept it. Search that is motivated by such outside options is pure rent-seeking. It causes costs, but only redistributes payoffs from the principal to the agent. The principal could eliminate the rent-seeking motive in a given period $t$ by promising the full surplus $Q^{*}$ in period $t+1$ to the agent. The agent would then only search for outside options with values above $Q^{*}$ so that his search effort $s_{t}$ would be efficient. However, this promise is not credible. In period $t+1$, the principal would earn a zero payoff, regardless of the agent's outside option. She then would like to renege on her promise and offer a different contract. Therefore, the agent invests too much into search under the optimal incentive contract.

To reduce rent-seeking, the principal offers an excessive bonus. As in the two period model, work effort increases in the bonus, while search effort decreases in the bonus. If $b_{t}>\Delta y$, further increasing the bonus creates benefits for the principal through lower search effort, but also costs since the principal has to compensate the agent for the costs of excessive effort. At $b_{t}=\Delta y$, increasing the bonus has first-order gains, but, by an envelope argument, only second-order costs. Thus, the optimal bonus strictly exceeds $\Delta y$. 
Offering an excessive bonus is expensive for the principal. An alternative way to curb search incentives would be to promise the agent a rent in the form of a positive payoff when the outside option value is zero or very small. The agent then has fewer incentives to avoid states in which he has no outside offer (or only a very unattractive one). In the rest of this subsection, we explore when the optimal incentive contract includes such promises.

We introduce two types of contracts that will allow us to test whether payoff promises are credible and profitable for the principal. First, under the "no-rent contract" $\sigma^{n r}$ (henceforth $n r$-contract) the principal offers in each period $t$ a wage $w_{t}$ that extracts all rents from the agent. Given the agent's expectations, $U_{t}=r_{t}$ for all $t$, the $n r$-contract specifies a bonus that maximizes the principal's expected payoff. This bonus is stationary, and the joint surplus under the $n r$-contract is therefore stationary as well. Denote by $w^{n r}\left(r_{t}\right)$ the wage, by $b^{n r}$ the bonus, and by $Q^{n r}$ the joint surplus under the optimal $n r$-contract. If in some period $t$ the agent accepts the $n r$-contract, the principal's total payoff is $Q^{n r}-r_{t}$, while the agent's total payoff is $r_{t}$. Since the $n r$-contract only uses the bonus to provide incentives and the bonus is contractible, the $n r$-contract is an equilibrium contract. Given that the agent expects that he will always only get the value of his outside option, there is no reason for the principal to pay more than the wage $w^{n r}\left(r_{t}\right)$ or to offer a different bonus. Hence, the agent's expectations are self-fulfilling.

Second, the principal may offer a "payoff floor contract" $\sigma^{\bar{u}}$. Under such a contract the principal offers on the equilibrium path the same bonus $b^{p f}$ in each period; in any period $t \geq 2$ with $d_{t}=1$, the wage $w_{t}$ is set so that $U_{t}\left(r_{t}\right)=\bar{u}$ if $r_{t} \leq \bar{u}$, and $U_{t}\left(r_{t}\right)=r_{t}$ if $r_{t}>\bar{u}$; in period $t=1$, the wage is set so that $U_{1}=0$. Thus, in the initial period, the principal extracts all rents from to the agent, but she promises a positive rent in future periods when the outside option value is below $\bar{u}$. Note that the $n r$-contract is a degenerate payoff floor contract with $\bar{u}=0$ and $b^{p f}=b^{n r}$. A payoff floor contract with $\bar{u}=Q^{f b}$ and $b^{p f}=\Delta y$ would realize all gains from trade, but, as we discussed above, it is not an equilibrium contract.

The promise of a payoff floor $\bar{u}>0$ reduces search incentives (provided it is credible). Under the $n r$-contract the first-order condition that characterizes search in period $t$ is given by

$$
\frac{\delta}{1-\delta} p^{\prime}\left(s_{t}\right) \int_{0}^{\infty} r_{t+1} g\left(r_{t+1}\right) d r_{t+1}=c_{s}\left(e_{t}, s_{t}\right)
$$

Under a payoff floor contract $\sigma^{\bar{u}}$, this first-order condition becomes

$$
\frac{\delta}{1-\delta} p^{\prime}\left(s_{t}\right)\left(\int_{\bar{u}}^{\infty} r_{t+1} g\left(r_{t+1}\right) d r_{t+1}-(1-G(\bar{u})) \bar{u}\right)=c_{s}\left(e_{t}, s_{t}\right)
$$

For any $\bar{u}>0$ the left-hand side of (16) is strictly smaller than that of (15). Thus, for given work effort, search incentives decrease in the payoff promise. We can show that in equilibrium 
work effort always increases in $\bar{u}$, while search effort always decreases in $\bar{u}, \frac{\partial e_{t}}{\partial \bar{u}}>0$ and $\frac{\partial s_{t}}{\partial \bar{u}}<0$; see the appendix for details.

A payoff floor $\bar{u}>0$ is credible only if it pays off for the principal to keep her promise in a period $t$ with $r_{t}=0$. In such a period, the principal's gains from the payoff floor must outweigh the costs of leaving a total payoff of $\bar{u}$ (instead of zero) to the agent. We construct a payoff floor contract by specifying that continuation play reverts to the $n r$-contract if the principal reneges on her promise. Intuitively, this means that if the principal does not keep her promise, the agent expects that she will extract all rents from him in all future periods.

We examine under what circumstances a payoff floor contract $\sigma^{\bar{u}}$ with $\bar{u}>0$ is an equilibrium contract by using a perturbation argument. Start with the $n r$-contract and slightly reduce the bonus from $b^{n r}$ to some value $b^{p f}<b^{n r}$. Then choose $\bar{u}$ so that search incentives remain constant, i.e., it is optimal for the agent to choose $s^{n r}$ provided that the bonus is $b^{p f}$ in each period and the principal always sets wages in $t \geq 1$ so that $U_{t}\left(r_{t}\right)=\bar{u}$ if $r_{t} \leq \bar{u}$, and $U_{t}\left(r_{t}\right)=r_{t}$ if $r_{t}>\bar{u}$. By construction, the agent then exerts less work effort than under the $n r$-contract; see the first-order condition (13). Since work effort under the $n r$-contract is excessive, this implies that the joint surplus increases. In other words, to reduce search incentives efficiently, the principal replaces a fraction of the excessive bonus by the promise of not fully exploiting the agent if his outside option value is zero or very small.

Observe that in period 1 and in a period $t$ with $d_{t}=1$ and $r_{t}>\bar{u}$, contract $\sigma^{\bar{u}}$ is strictly better for the principal than the $n r$-contract. The joint surplus $Q_{t}$ is larger under $\sigma^{\bar{u}}$, but the agent's total payoff $U_{t}\left(r_{t}\right)$ is just the same as under the $n r$-contract. In a period $t$ with $d_{t}=1$ and $r_{t}<\bar{u}$, the payoff floor creates first-order costs for the principal. Whether current and future (expected) gains from the payoff floor exceed the costs of keeping the promise, depends on the production and cost functions as well as on the discount factor. We can show that there exists a payoff floor contract $\sigma^{\bar{u}}$ with $\bar{u}>0$ that is an equilibrium contract if

$$
\begin{gathered}
(1-\delta) \frac{d e_{t}}{d b_{t}} f^{\prime}\left(e_{t}\right)\left(\Delta y-b_{t}\right)-\frac{d \bar{u}}{d b_{t}}+\frac{\delta\left[\left(1-p\left(s^{n r}\right)\right)+p\left(s^{n r}\right) G\left(Q^{n r}\right)\right]}{1-\delta\left[\left(1-p\left(s^{n r}\right)\right)+p\left(s^{n r}\right) G\left(Q^{n r}\right)\right]} \\
\quad \times\left((1-\delta) \frac{d e_{t}}{d b_{t}} f^{\prime}\left(e_{t}\right)\left(\Delta y-b_{t}\right)-\left(1-p\left(s^{n r}\right)\right) \frac{d \bar{u}}{d b_{t}}\right)<0
\end{gathered}
$$

at $\sigma^{n r}$ (we derive this term in the proof of Proposition 3). The first term in (17) captures the gains through the reduction in excessive effort; the second term is the payoff floor that is needed to keep search effort constant when the bonus is reduced; ${ }^{15}$ the third term scales up the value of future gains by the discount factor and the continuation probability of the relationship; and the fourth term (in large brackets) captures future gains from the payoff floor. Note that

\footnotetext{
${ }^{15}$ We have $\frac{d s_{t}}{d \bar{u}} d \bar{u}=-\frac{d s_{t}}{d b_{t}} d b_{t}$ so that $\frac{d \bar{u}}{d b_{t}}=-\frac{d s_{t}}{d b_{t}}\left(\frac{d s_{t}}{d \bar{u}}\right)^{-1}$.
} 
the fourth term is identical to the first two terms except that the costs of the payoff floor are weighted by their probability of occurrence.

We define the set of primitives $\left\{y, \bar{y}, f, p, c\left(e_{t}, s_{t}\right), \delta, G\right\}$ as an "environment." The inequality in (17) is satisfied if the environment exhibits the following features: The probability of receiving an offer $p\left(s^{n r}\right)$ is large enough so that the principal has to pay the payoff floor infrequently, and $\delta G\left(Q^{n r}\right)$ is sufficiently close to one so that the principal values the future benefits of the payoff floor (and, in expectation, the relationship endures for many periods); note that $G\left(Q^{n r}\right)$ is close to one if most outside options have small values relative to the project payoffs $\underline{y}, \bar{y}$. If inequality (17) holds, there is a non-empty, closed, and bounded set $\Lambda \in \mathbb{R}^{+} \times \mathbb{R}^{+}$of bonus and payoff floor combinations $\left(b^{p f}, \bar{u}\right)$ that define payoff floor equilibrium contracts. By continuity, there then exists a combination $\left(b^{p f^{*}}, \bar{u}^{*}\right) \in \Lambda$ with positive $\bar{u}^{*}$ that defines an optimal payoff floor contract. Our second main result is as follows:

Proposition 3. There is an open set of environments for which inequality (17) is satisfied. In such an environment, an optimal incentive contract has the property that the agent receives a rent, i.e., for any period $t>1$ with $d_{t}=1$ we have $U_{t}^{*}\left(r_{t}\right)>r_{t}$ for some positive measure of values $r_{t}$.

In our setup, there always exists a payoff floor contract that is also an optimal incentive contract (the payoff floor of this contract may be zero, so that it is a $n r$-contract). Consider a contract that promises the agent payoffs above his reservation value in some periods. Suppose that for a positive measure of outside option values the agent receives a payoff that lies above his outside option value and above his payoff when his outside option has zero value, $U_{t}\left(r_{t}\right)>$ $\max \left\{U_{t}(0), r_{t}\right\}$. Such a contract cannot be optimal because it generates search incentives that are too strong. That is, by rearranging incentives, we can reduce the excessive work effort while keeping the agent's search effort constant. We therefore get the following result. ${ }^{16}$

Proposition 4. There is a payoff floor contract with (excessive) bonus $b^{p f^{*}}$ and payoff floor $\bar{u}^{*} \geq 0$ that is an optimal incentive contract.

We can now describe how the agent's costly search for better job opportunities changes the optimal incentive contract. We consider two benchmark cases. First, assume that search is impossible, $c\left(e_{t}, s_{t}\right)=\infty$ for all $s_{t}>0$ (e.g., there are no positions for the agent in other firms), or that search is costless, $c\left(e_{t}, s_{t}\right)=c\left(e_{t}, 0\right)$ for all $s_{t}>0$ (there are many positions for the agent in firms that are close nearby). In both cases, the agent's search effort does not depend on the bonus. The optimal incentive contract then implements the first-best allocation by paying the

\footnotetext{
${ }^{16}$ This result may not hold when search effort also changes the distribution over outside option values $G$.
} 
agent the full marginal surplus, $b_{t}=\Delta y$, in each period $t$, and extracts all rents from the agent through the wage. Next, assume that search is costly, but that there is no multitasking problem so that $c_{e s}\left(e_{t}, s_{t}\right)=0$ for all $e_{t}, s_{t}$. The equilibrium search effort $s_{t}$ is then again independent of the bonus $b_{t}$, and the optimal contract implements the first-best work effort by offering $b_{t}=\Delta y$ in each period $t$; depending on the primitives, it may also offer payoff promises to reduce search that is motivated by rent-seeking. Therefore, the optimal incentive contract offers both an excessive bonus and payoff promises only if search is costly and there is a multitasking problem. Hence, our model suggests that high bonuses and wages may jointly occur due to on-the-job search.

\section{Extensions}

To simplify the exposition of the model, we made a number of assumptions. In this section, we consider several extensions in which we relax some of them. In Subsection 5.1, we examine the baseline model with discretionary bonus payments. In Subsection 5.2, we assume that the agent is protected by limited liability. Finally, in Subsection 5.3, we discuss what happens to the optimal incentive contract if search effort increases the chance of finding an outside option in several subsequent periods.

\subsection{Non-Contractible Bonus}

In our baseline model, we assumed that the output is verifiable and the bonus enforceable. However, in many jobs, performance is difficult to objectively evaluate or verify to third parties. The relational contracts literature (e.g., Levin 2003) therefore analyzes optimal incentives when performance measures are non-verifiable. In the following, we show that our main result still holds if we drop the assumption of a contractible bonus.

We update the setting from Section 3 so that the bonus is discretionary. In a contract offer $\left(w_{t}, b_{t}\right)$, the term $b_{t}$ now represents a promised bonus. After the output $y_{t}$ is realized, the principal pays the wage $w_{t}$ and chooses the realized bonus, which can be equal to $b_{t}$ or any other non-negative value. ${ }^{17}$ Both principal and agent can condition their actions on past bonus promises and realized bonus payments. In this setting, a promised bonus provides work incentives in equilibrium only if it is self-enforcing, i.e., it must be in the principal's best interest to pay the promised bonus. This constraint typically limits the size of the bonus.

We first define a continuation equilibrium $\sigma^{z}$ for the case that the principal reneges on her bonus promise. In this equilibrium, the agent believes that the principal will never pay a bonus.

\footnotetext{
${ }^{17}$ For convenience, we do not explicitly introduce notation for the realized bonus.
} 
Additionally, he assumes that in each period the principal offers a wage that makes the agent indifferent between the principal's contract and his outside option. Given these beliefs, it is optimal for the agent to exert no work effort, $e_{t}=0$, and to choose search effort $s_{t}$ so that $\frac{\delta}{1-\delta} p^{\prime}\left(s_{t}\right) \mathbb{E}_{G}\left[r_{t}\right]=c_{s}\left(0, s_{t}\right)$. Denote by $s^{z}$ the optimal search effort and by $Q^{z}$ the joint surplus in the relationship if in each period $t$ the agent exerts effort $e_{t}=0, s_{t}=s^{z}$ and $d_{t}=1$ if and only if $r_{t} \leq Q^{z}$. Given the agent's strategy, it is then indeed optimal for the principal to never pay a bonus and to extract all rents from the agent.

Consider the $n r$-contract from the last section. In the current setting, it is no longer clear whether the principal can credibly promise to pay the bonus $b^{n r}$ after a high output. Suppose that continuation play is given by $\sigma^{z}$ if the principal reneges on her promise. It is then rational for her to pay the promised bonus $b^{n r}$ if and only if

$$
\begin{aligned}
-(1-\delta) b^{n r} & +\delta\left(1-p\left(s^{n r}\right)\right) Q^{n r}+\delta p\left(s^{n r}\right) G\left(Q^{n r}\right)\left(Q^{n r}-\mathbb{E}_{G}\left[r_{t+1} \mid r_{t+1} \leq Q^{n r}\right]\right) \\
& \geq \delta\left(1-p\left(s^{n r}\right)\right) Q^{z}+\delta p\left(s^{n r}\right) G\left(Q^{z}\right)\left(Q^{z}-\mathbb{E}_{G}\left[r_{t+1} \mid r_{t+1} \leq Q^{z}\right]\right) .
\end{aligned}
$$

We can show that this inequality is satisfied if (i) the probability of continuation of the relationship $G\left(Q^{n r}\right)$ is high, (ii) the discount factor $\delta$ is close to 1 , and (iii) $\Delta y$ is large relative to $\mathbb{E}_{G}\left[r_{t}\right] \frac{c_{e s}\left(e^{n r}, s^{n r}\right)}{c_{s s}\left(e^{n r}, s^{n r}\right)}$ so that work effort is important for the joint surplus, while the bonus $b^{n r}$ is not too large; see the proof of Proposition 5 for details. Thus, a $n r$-contract can be an equilibrium contract in the setting with non-contractible bonus.

Suppose that a $n r$-contract is an equilibrium contract. In this case, it is straightforward to show that if additionally condition (17) is satisfied, then a payoff floor contract exists that is an equilibrium contract and strictly better for the principal than the $n r$-contract. Under a payoff floor contract, the principal has to keep two promises: first, to always offer a wage that implements the payoff floor, and second, to pay the bonus $b^{p f}$ in case of high output. We can specify that if the principal reneges on any of these promises, then continuation play is given by $\sigma^{z}$. Both condition (17) and condition (18) can be satisfied simultaneously so that a payoff floor contract can be an optimal incentive contract when the output is non-verifiable. In fact, the set of payoff floors $\bar{u}$ which can occur in equilibrium is larger in the current setting than in the baseline model since the continuation equilibrium $\sigma^{z}$ is strictly worse for the principal than $\sigma^{n r}$. We therefore can have a relational contract model in which the optimal incentive contract may exhibit both excessive bonuses and efficiency wages.

Proposition 5. Consider the model with non-contractible bonus. If condition (18) holds, there is a nr-contract that is an equilibrium contract. An optimal incentive contract then has the following properties.

(a) The joint surplus is stationary and independent of the outside option, $Q_{t}^{*}\left(r_{t}\right)=Q^{*}$. In all 
periods $t$ in which the agent works for the principal, the joint surplus is not maximized, $Q^{*}<Q^{f b}$, and the bonus is excessive, $b_{t}^{*}\left(r_{t}\right)>\Delta y$.

(b) If additionally condition (17) holds, the agent receives a rent, i.e., for any period $t>1$ with $d_{t}=1$ we have $U_{t}^{*}\left(r_{t}\right)>r_{t}$ for some positive measure of values $r_{t}$.

\subsection{Limited Liability}

The assumption of unlimited liability ensures that the principal can increase the bonus while keeping the agent's payoff constant by lowering the wage. Thus, under the optimal incentive contract, the wage $w_{t}$ can be negative if the outside option value $r_{t}$ is close enough to zero. However, in many jobs, negative or very low wages are not feasible, for example, because of minimum wage requirements or because employees lack the financial resources to cover negative wages (e.g., franchising fees). In this subsection, we analyze our baseline model under the assumption of limited liability. We show that the optimal incentive contract then again may pay excessive bonuses and positive rents to the agent.

We consider the original setting under the assumption of limited liability. In each period $t$, the contract $\left(w_{t}, b_{t}\right)$ must satisfy the constraints $w_{t} \geq \bar{w}$ and $w_{t}+b_{t} \geq \bar{w}$ for some $\bar{w} \in \mathbb{R}$. Note that all else being equal, the optimal contract in this setting is the same as in the baseline setting if $\bar{w}$ is sufficiently small. In the following, we therefore assume that $\bar{w}=0$ so that limited liability may change the optimal contract. Lemma 1 remains valid in this setting. Any incentive effect that can be achieved through a variation in the agent's continuation value can also be generated through a raise in the bonus. Thus, we can again focus on equilibria in which the agent's total payoff in period $t$ only depends on the realized outside option value $r_{t}$.

Recall the $n r$-contract from the baseline model. This contract cannot be an equilibrium contract since it pays a negative wage when the agent's outside option value is zero, $w^{n r}(0)<0$. Thus, the bonus of the optimal contract - and hence the joint surplus - may vary with the agent's outside option value. Let $\sigma^{l l}$ be an optimal contract and denote by $w_{t}^{l l}\left(r_{t}\right), b_{t}^{l l}\left(r_{t}\right)$ the wage and bonus that are paid on the equilibrium path in period $t$ when the agent's outside option is $r_{t}$. Let $U_{t}^{l l}\left(r_{t}\right)$ be the agent's corresponding total utility, and $Q_{t}^{l l}\left(r_{t}\right)$ the joint surplus in period $t$. Let $Q_{t}^{\max }$ be the highest value of $r_{t}$ in period $t$ so that the agent accepts the principal's contract (we assume that in case of indifference he works for the principal). Then the wage $w_{t}^{l l}\left(r_{t}\right)$ and the bonus $b_{t}^{l l}\left(r_{t}\right)$ are chosen to maximize

$$
\begin{aligned}
V_{t}^{l l}\left(r_{t}\right)= & (1-\delta)\left(\underline{y}-w_{t}+f\left(e_{t}\right)\left(\Delta y-b_{t}\right)\right)+\delta\left(1-p\left(s_{t}\right)\right)\left(Q_{t+1}^{l l}(0)-U_{t+1}^{l l}(0)\right) \\
& +\delta p\left(s_{t}\right) G\left(Q_{t+1}^{\max }\right) \mathbb{E}_{G}\left[Q_{t+1}^{l l}\left(r_{t+1}\right)-U_{t+1}^{l l}\left(r_{r+1}\right) \mid r_{t+1} \leq Q_{t+1}^{\max }\right]
\end{aligned}
$$


subject to the agent's incentive constraints in (13), (14), the constraint that the agent gets his equilibrium level of utility,

$$
\begin{aligned}
\max _{e_{t}, s_{t}} & (1-\delta)\left(w_{t}+f\left(e_{t}\right) b_{t}-c\left(e_{t}, s_{t}\right)\right)+\delta\left(1-p\left(s_{t}\right)\right) U_{t+1}^{l l}(0) \\
& +\delta p\left(s_{t}\right) G\left(Q_{t+1}^{\max }\right) \mathbb{E}_{G}\left[U_{t+1}^{l l}\left(r_{r+1}\right) \mid r_{r+1} \leq Q_{t+1}^{\max }\right] \\
& +\delta p\left(s_{t}\right)\left(1-G\left(Q_{t+1}^{\max }\right)\right) \mathbb{E}_{G}\left[r_{r+1} \mid r_{r+1}>Q_{t+1}^{\max }\right] \geq U_{t}^{l l}\left(r_{t}\right),
\end{aligned}
$$

and the limited liability constraints. With this, we can show two features of the optimal contract. First, for large outside option values the bonus must be excessive. Intuitively, this is the case because in order to match the agent's outside option, the principal has to pay a positive wage $w_{t}$ when $r_{t}$ is large. The limited liability constraint is then no longer binding so that (by the same logic as in the baseline model) the optimal bonus exceeds $\Delta y$. Second, for small values of the outside option $r_{t}$ the agent must earn a rent in the sense that $U_{t}^{l l}\left(r_{t}\right)>r_{t}$. The optimal wage at small $r_{t}$ is zero due to limited liability, but the optimal bonus is strictly positive. Since $U_{t}^{l l}\left(r_{t}\right)>0$ for all $t$ and $r_{t}$, the agent's participation constraint is not binding when $r_{t}$ is small or zero. Thus, there is a payoff floor that reduces search incentives.

Proposition 6. Consider the model with limited liability. An optimal incentive contract has the following properties. If for given parameters the low output y is sufficiently large, then in all periods $t$ in which the agent works for the principal

(a) the bonus is excessive whenever the outside option value $r_{t}$ is sufficiently large, and

(b) the agent receives a rent, $U_{t}^{*}\left(r_{t}\right)>r_{t}$, whenever the outside option value $r_{t}$ is sufficiently close to zero.

Note that limited liability creates the payoff floor mechanically. In the canonical principalagent model, it is a standard result that the agent earns a rent if he is risk neutral and protected by limited liability. In contrast, the payoff floor in our basic model without limited liability originates only from dynamic considerations: The principal promises a payoff floor for period $t+1$ so that the agent spends less effort on search in period $t$.

\subsection{Dynamic Effects of Search Effort}

In our baseline model, search in period $t$ only has an effect on the probability of finding an outside offer in period $t+1$. This assumption may be somewhat strict since previous job search may result in personal relationships that are useful for future search efforts. Suppose now that search in period $t$ increases the probability of finding an outside option in all periods $t+1, t+$ 
$2, \ldots, t+T$ for some finite $T \in \mathbb{N}$. This probability is now given by a function $p_{t}\left(s_{t-1}, \ldots, s_{t-T}\right)$. In general, previous search then affects search incentives in the current period so that the optimal contract may be non-stationary (and thus more cumbersome to characterize). However, we can show for a special case that our main result holds when search has dynamic effects on the outside option value. Let the search technology be given by $p_{t}\left(s_{t-1}, \ldots, s_{t-T}\right)=p^{\prime} \sum_{\tau=1}^{T} \alpha_{\tau} s_{t-\tau}$ for some value $p^{\prime}>0$ and positive values $\left(\alpha_{1}, \ldots, \alpha_{T}\right){ }^{18}$ Suppose that in equilibrium wage and bonus in period $t$ only depend on the outside option value $r_{t}$. Then the agent's first-order condition for optimal search effort in period $t$ is

$$
\frac{1}{1-\delta} p^{\prime} \sum_{\tau=1}^{T} \alpha_{\tau} \sum_{\tau=1}^{T} \delta^{\tau}\left(\mathbb{E}_{G}\left[U_{t+\tau}\left(r_{t+\tau}\right)\right]-U_{t+\tau}(0)\right)=c_{s}\left(e_{t}, s_{t}\right) .
$$

The first-order condition for optimal work effort is again given by (13). Thus, both work and search effort in period $t$ are independent of previous search efforts. Observe that we have $\mathbb{E}_{G}\left[U_{t}\left(r_{t}\right)\right]=r_{t}$ in any equilibrium in which the principal extracts all rents from the agent in all periods. In such an equilibrium, the search effort is implicitly defined by (21). Thus, the $n r$-contract $\sigma^{n r}$ is an equilibrium contract, and it exhibits the same features as in the baseline model. The optimal payoff floor contract $\sigma^{\bar{u}^{*}}$ is also an equilibrium contract since we can specify that continuation play is given by $\sigma^{n r}$ if the principal fails to offer the wage/bonus combination prescribed by $\sigma^{\bar{u}^{*}}$. We therefore obtain the same results as in the baseline model.

\section{Conclusion}

In this paper, we investigated how the shape of the optimal incentive contract is affected when workers can generate competition for their services through on-the-job search. The importance of job-to-job transitions in today's labor markets suggests that on-the-job search is a significant issue for many employers. We showed that costly on-the-job search affects the incentive problem inside organizations in meaningful ways. It creates value if its only motivation is a better worker-firm match. However, the agent can use outside offers from less productive relationships to negotiate a better deal with his principal. This rent-seeking motive causes the agent to invest too many resources in on-the-job search. The optimal incentive contract may reduce rent-seeking by offering both excessive performance pay and efficiency wages. The latter may come in the form of payoff floors: The principal then does not extract all rents from the agent if his current outside option value is very small. Both measures reduce the agent's search incentives (but they are not perfect substitutes). Nevertheless, there is rent-seeking under the

\footnotetext{
${ }^{18} \mathrm{We}$ assume that $p^{\prime}$ is small enough such that optimal search effort is given by an interior solution.
} 
optimal contract. Therefore, on-the-job search creates agency costs.

\section{References}

Aнn, H. J., Sнао, L., 2017. Precautionary On-the-Job Search over the Business Cycle. Finance and Economics Discussion Series 2017-25. Washington: Board of Governors of the Federal Reserve System.

Akerlof, G., 1982. Labor Contracts as Partial Gift Exchange. Quart. J. Econ. 97 (4), 543-569.

Arellano, M., Meghir, C., 1992. Female Labour Supply and On-the-Job Search: An Empirical Model Estimated Using Complementary Data Sets. Rev. Econ. Stud. 59 (3), 537-559.

Baker, G., Gibbons, R., Murphy, K., 2002. Relational Contracts and the Theory of the Firm. Quart. J. Econ. 117 (1), 39-84.

Barron, J., Berger, M., Black, D., 2006. Selective Counteroffers. J. Lab. Econ. 24 (3), 385409.

Bénabou, R., Tirole, J., 2016. Bonus Culture: Competitive Pay, Screening, and Multitasking. J. Polit. Economy 124 (2), 305-370.

Bertrand, M., Mullainathan, S., 2001. Are CEOS Rewarded for Luck? The Ones without Principals Are. Quart. J. Econ. 116 (3), 901-932.

Botrd, S., Meyer-ter Vehn, M. 2015. Relational Contracts in Competitive Labour Markets. Rev. Econ. Stud. 82 (2), 490-534.

Bull, C., 1987. The Existence of Self-Enforcing Implicit Contracts. Quart. J. Econ. 102(1), 147-160.

Burdett, K., Mortensen, D., 1998. Wage Differentials, Employer Size, and Unemployment. Int. Econ. Rev. 39 (2), 257-273.

Carnahan, S., Agarwal, R., Campbell, B., 2012. Heterogeneity in turnover: The effect of relative compensation dispersion of firms on the mobility and entrepreneurship of extreme performers. Strategic Manage. J. 33 (12), 1411-1430.

Chassang, S., 2010. Building Routines: Learning, Cooperation, and the Dynamics of Incomplete Relational Contracts. Am. Econ. Rev. 100 (1), 448-465. 
Christensen, B. J., Lentz, R., Mortensen, D., Neumann, G., Werwatz, A., 2005. On-the-Job Search and the Wage Distribution. J. Lab. Econ. 23 (1), 31-58.

Elfenbein, D., Hamilton, B., Zenger, T., 2010. The Small Firm Effect and the Entrepreneurial Spawning of Scientists and Engineers. Manag. Sci. 56 (4), 659-681.

Englmaier, F., Muehlheusser, G., Roider, A., 2014. Optimal incentive contracts for knowledge workers. Europ. Econ. Rev. 67, 82-106.

Fallick, B., Fleischman, C., 2004. Employer-to-Employer Flows in the US Labor Market: The Complete Picture of Gross Worker Flows. Vol. 4. Division of Research \& Statistics and Monetary Affairs, Federal Reserve Board.

Fallick, B., Fleischman, C., Rebitzer, J., 2006. Job-Hopping in Silicon Valley: Some Evidence concerning the Microfoundations of a High-Technology Cluster. Rev. Econ. Statist. 88 (3), 472-481.

Friebel, G., Giannetti, M., 2009. Fighting for Talent: Risk-Taking, Corporate Volatility and Organisation Change. Econ. J. 119 (540), 1344-1373.

Fuchs, W., 2007. Contracting with Repeated Moral Hazard and Private Evaluations. Am. Econ. Rev. 97 (4), 1432-1448.

Halac, M., 2012. Relational Contracts and the Value of Relationships. Am. Econ. Rev. 102 (2), $750-779$.

Holmström, B., Milgrom, P., 1991. Multitask Principal-Agent Analyses: Incentive Contracts, Asset Ownership, and Job Design. J. Law Econ. Organ. 7, 24-52.

Hvide, H., Kristiansen, E. G., 2012. Management of Knowledge Workers. J. Law Econ. 55 (4), 815-838.

Lazear, E., Shaw, K., 2007. Personnel Economics: The Economist's View of Human Resources. J. Econ. Perspect. 21 (4), 91-114.

Lemieux, T., Macleod, B., Parent, D., 2009. Performance Pay and Wage Inequality. Quart. J. Econ. 124 (1), 1-49.

LENTz, R., 2010. Sorting by search intensity. J. Econ. Theory 145 (4), 1436-1452.

Lentz, R., 2014. Optimal Employment Contracts with Hidden Search. NBER Working Paper No. 19988. 
Levin, J., 2003. Relational Incentive Contracts. Am. Econ. Rev. 93 (3), 835-857.

Li, J., Matouschek, N., 2010. Managing Conflicts in Relational Contracts. Am. Econ. Rev. 103 (6), 2328-2351.

Lise, J., 2013. On-the-Job Search and Precautionary Savings. Rev. Econ. Stud. 80 (3), 10861113.

MacLeod, B., Malcomson, J., 1989. Implicit Contracts, Incentive Compatibility, and Involuntary Unemployment. Econometrica 57 (2), 447-480.

MacLeod, B., Malcomson, J., 1998. Motivation and Markets. Am. Econ. Rev. 88 (3), 388-411.

Maestri, L., 2012. Bonus Payments versus Efficiency Wages in the Repeated Principal-Agent Model with Subjective Evaluations. Am. Econ. J. Micro. 4 (3), 34-56.

Moen, E., Rosén, Å., 2013. On-the-Job Search and Moral Hazard. J. Europ. Econ. Assoc. 11 (6), 1404-1431.

Mortensen, D., 1978. Specific Capital and Labor Turnover. Bell J. Econ. 9 (2), 572-586.

Mueller, A., 2010. On-the-job search and wage dispersion: New evidence from time use data. Econ. Letters 109 (2), 124-127.

Pissarides, C., 1994. Search Unemployment with On-the-job Search. Rev. Econ. Stud. 61 (3), $457-475$.

Pissarides, C., Wadsworth, J., 1994. On-the-job search: Some empirical evidence from Britain. Europ. Econ. Rev. 38 (2), 385-401.

Postel-Vinay, F., Robin, J.-M., 2004. To Match or Not To Match? Optimal Wage Policy with Endogenous Worker Search Intensity. Rev. Econ. Dynam. 7 (2), 297-330.

SAlop, S., 1979. A Model of the Natural Rate of Unemployment. Am. Econ. Rev. 69 (1), 117125.

SchöttNer, A., 2008. Relational Contracts, Multitasking, and Job Design. J. Law Econ. Organ. $24(1), 138-162$.

Shapiro, C., Stiglitz, J., 1984. Equilibrium Unemployment as a Worker Discipline Device. Am. Econ. Rev. 74 (3), 433-444.

Stevenson, B., 2008. The Internet and Job Search. NBER Working Paper No. 13886. 
Stewart, J., 2002. Recent Trends in Job Stability and Job Security: Evidence from the March CPS. US Department of Labor, Bureau of Labor Statistics, Office of Employment and Unemployment Statistics, Working Paper 356.

Stiglitz, J., 1974. Alternative Theories of Wage Determination and Unemployment in LDC's: The Labor Turnover Model. Quart. J. Econ. 88 (2), 194-227.

Tsuyuhara, K., 2016. Dynamic contracts with worker mobility via directed on-the-job search. Int. Econ. Rev. 57 (4), 1405-1424.

Weiss, A., 1980. Job Queues and Layoffs in Labor Markets with Flexible Wages. J. Polit. Economy 88 (3), 526-538.

Yamaguchi, S., 2010. Job Search, Bargaining, and Wage Dynamics. J. Lab. Econ. 28 (3), 595631.

\section{Appendix}

Proof of Lemma 1. Let $\sigma=\left(\sigma_{P}, \sigma_{A}\right)$ be given and assume that history $h_{t}^{0}$ is reached upon which the principal offers the contract $\left(w_{t}, b_{t}\right)$. Denote by $U_{t+1}\left(y_{t}, r_{t+1}\right)$ the agent's continuation value in period $t+1$ if the outcome in period $t$ was $y_{t}$ and his outside option value in period $t+1$ is $r_{t+1}$. The agent's effort choices $e_{t}^{*}, s_{t}^{*}$ solve

$$
\begin{aligned}
\max _{e_{t}, s_{t}} & (1-\delta)\left(f\left(e_{t}\right) b_{t}-c\left(e_{t}, s_{t}\right)\right)+\delta\left(1-p\left(s_{t}\right)\right)\left[f\left(e_{t}\right) U_{t+1}(\bar{y}, 0)+\left(1-f\left(e_{t}\right)\right) U_{t+1}(\underline{y}, 0)\right] \\
& +\delta p\left(s_{t}\right) \mathbb{E}_{G}\left[f\left(e_{t}\right) U_{t+1}\left(\bar{y}, r_{t+1}\right)+\left(1-f\left(e_{t}\right)\right) U_{t+1}\left(\underline{y}, r_{t+1}\right)\right] .
\end{aligned}
$$

Define

$$
\hat{b}_{t}=\frac{\delta}{1-\delta}\left(1-p\left(s_{t}\right)\right)\left[U_{t+1}(\bar{y}, 0)-U_{t+1}(\underline{y}, 0)\right]+\frac{\delta}{1-\delta} p\left(s_{t}\right) \mathbb{E}_{G}\left[U_{t+1}\left(\bar{y}, r_{t+1}\right)-U_{t+1}\left(\underline{y}, r_{t+1}\right)\right] .
$$

We can rewrite the problem in (22) as

$$
\max _{e_{t}, s_{t}}(1-\delta)\left(f\left(e_{t}\right)\left(b_{t}+\hat{b}_{t}\right)-c\left(e_{t}, s_{t}\right)\right)+\delta\left(1-p\left(s_{t}\right)\right) U_{t+1}(\underline{y}, 0)+\delta p\left(s_{t}\right) \mathbb{E}_{G}\left[U_{t+1}\left(\underline{y}, r_{t+1}\right)\right]
$$

Consider the alternative profile $\hat{\sigma}=\left(\hat{\sigma}_{P}, \hat{\sigma}_{A}\right)$ where $\hat{\sigma}_{P}$ is identical to $\sigma_{P}$ except that after history $h_{t}^{0}$ the principal offers contract $\left(w_{t}, b_{t}+\hat{b}_{t}\right)$ and her continuation play after any outcome $y_{t}$ equals that under $\sigma_{P}$ when $y_{t}=y$; $\hat{\sigma}_{A}$ is identical to $\sigma_{A}$ except that the agent accepts the contract after history $h_{t}^{1}=\left(h_{t}^{0}, w_{t}, b_{t}+\hat{b}_{t}\right)$ and then exerts work effort $e_{t}^{*}$ and search effort $s_{t}^{*}$; 
his continuation play after any outcome $y_{t}$ equals that under $\sigma_{A}$ when $y_{t}=\underline{y}$. By construction, $\hat{\sigma}$ is an equilibrium and payoff equivalent to $\sigma$.

Marginal effects of bonus $b_{t}$ and payoff floor $\bar{u}$ on period-t work and search effort. Consider a period $t$ with $d_{t}=1$. Suppose there is a payoff floor in the sense that for some $\bar{u} \geq 0$ we have $U_{t+1}\left(r_{t+1}\right)=\bar{u}$ if $r_{t+1} \leq \bar{u}$, and $U_{t+1}\left(r_{t+1}\right)=r_{t+1}$ if $r_{t+1}>\bar{u}$. The agent's problem then is

$$
\begin{aligned}
\max _{e_{t}, s_{t}} & (1-\delta)\left(w_{t}+f\left(e_{t}\right) b_{t}-c\left(e_{t}, s_{t}\right)\right)+\delta\left(1-p\left(s_{t}\right)\right) \bar{u} \\
& +\delta p\left(s_{t}\right) G(\bar{u}) \bar{u}+\delta p\left(s_{t}\right)(1-G(\bar{u})) \mathbb{E}_{G}\left[r_{t+1} \mid r_{t+1} \geq \bar{u}\right]
\end{aligned}
$$

The agent's optimal choices are thus characterized by the first-order conditions

$$
\begin{gathered}
f^{\prime}\left(e_{t}\right) b_{t}-c_{e}\left(e_{t}, s_{t}\right)=0, \\
\frac{\delta}{1-\delta} p^{\prime}\left(s_{t}\right)\left(-\bar{u}+G(\bar{u}) \bar{u}+(1-G(\bar{u})) \mathbb{E}_{G}\left[r_{t+1} \mid r_{t+1} \geq \bar{u}\right]\right)-c_{s}\left(e_{t}, s_{t}\right)=0 .
\end{gathered}
$$

Using the implicit function theorem we then get

$$
\begin{aligned}
\frac{d e_{t}}{d b_{t}} & =\frac{-c_{s s}\left(e_{t}, s_{t}\right) f^{\prime}\left(e_{t}\right)}{c_{s s}\left(e_{t}, s_{t}\right)\left(f^{\prime \prime}\left(e_{t}\right) b_{t}-c_{e e}\left(e_{t}, s_{t}\right)\right)+c_{e s}\left(e_{t}, s_{t}\right)^{2}}>0, \\
\frac{d s_{t}}{d b_{t}} & =\frac{c_{e s}\left(e_{t}, s_{t}\right) f^{\prime}\left(e_{t}\right)}{c_{s s}\left(e_{t}, s_{t}\right)\left(f^{\prime \prime}\left(e_{t}\right) b_{t}-c_{e e}\left(e_{t}, s_{t}\right)\right)+c_{e s}\left(e_{t}, s_{t}\right)^{2}}<0,
\end{aligned}
$$

where the inequalities follow from the assumptions on the production and cost functions. With respect to the payoff floor $\bar{u}$ we get

$$
\begin{aligned}
\frac{d e_{t}}{d \bar{u}} & =\frac{-\frac{\delta}{1-\delta} p^{\prime}\left(s_{t}\right)(1-G(\bar{u})) c_{e s}\left(e_{t}, s_{t}\right)}{c_{s s}\left(e_{t}, s_{t}\right)\left(f^{\prime \prime}\left(e_{t}\right) b_{t}-c_{e e}\left(e_{t}, s_{t}\right)\right)+c_{e s}\left(e_{t}, s_{t}\right)^{2}}>0, \\
\frac{d s_{t}}{d \bar{u}} & =\frac{-\frac{\delta}{1-\delta} p^{\prime}\left(s_{t}\right)(1-G(\bar{u}))\left(f^{\prime \prime}\left(e_{t}\right) b_{t}-c_{e e}\left(e_{t}, s_{t}\right)\right)}{c_{s s}\left(e_{t}, s_{t}\right)\left(f^{\prime \prime}\left(e_{t}\right) b_{t}-c_{e e}\left(e_{t}, s_{t}\right)\right)+c_{e s}\left(e_{t}, s_{t}\right)^{2}}<0 .
\end{aligned}
$$

We use these terms throughout the paper.

Proof of Proposition 2. By Lemma 1 we can focus on contracts in which the principal's and agent's total payoff at the beginning of period $t$ only depends on $r_{t}$. The proof proceeds in steps. Step 1. We show that the joint surplus under the optimal contract is stationary and independent of the outside option, $Q_{t}^{*}\left(r_{t}\right)=Q^{*}$. Consider any period $t$ in which the agent works for the principal. Under the optimal contract, wage $w_{t}$ and bonus $b_{t}$ are chosen to maximize $V_{t}\left(r_{t}\right)=Q_{t}\left(r_{t}\right)-U_{t}\left(r_{t}\right)$. Note that for given expectations about $U_{t+1}\left(r_{t+1}\right)$ the only variable that influences $Q_{t}\left(r_{t}\right)$ is the bonus $b_{t}$. We can vary $b_{t}$ while keeping $U_{t}\left(r_{t}\right)$ fixed by adjusting $w_{t}$. Thus, $Q_{t}\left(r_{t}\right)$ is independent of $r_{t}$ under an optimal contract. Assume by contradiction that there 
are two periods, $t$ and $t^{\prime}$, so that on the equilibrium path of an optimal contract it can happen that $d_{t}=d_{t^{\prime}}=1$ and $Q_{t}<Q_{t^{\prime}}$. Then we can increase the principal's payoff by continuing play in period $t$ like in period $t^{\prime}$ and choosing $w_{t}$ so that the original payoff promises in $U_{t}\left(r_{t}\right)$ are fulfilled. Therefore, the joint surplus in the relationship under an optimal contract must be stationary. Step 2. We show that the optimal contract does not maximize the joint surplus. Suppose by contradiction that it does. Then, in each period $t$ with $d_{t}=1$, we must have $Q_{t}^{*}=Q^{f b}$ and $d_{t}=1$ if $r_{t}<Q^{f b}$ as well as $d_{t}=0$ if $r_{t}>Q^{f b}$. When $d_{t}=1$, this is only possible if the agent has first-best work effort incentives, $b_{t}^{*}=\Delta y$, and first-best search effort incentives,

$$
\frac{\delta}{1-\delta} p^{\prime}\left(s^{f b}\right)\left(1-G\left(Q^{f b}\right)\right)\left(\mathbb{E}_{G}\left[r_{t+1} \mid r_{t+1} \geq Q^{f b}\right]-Q^{f b}\right)=c_{s}\left(e^{f b}, s^{f b}\right) .
$$

The latter is possible only if $U_{t}\left(r_{t}\right)=Q^{f b}$ whenever $d_{t}=1$ and $r_{t}<Q^{f b}$. This implies that the agent receives the entire rent from the project. Promising the entire rent to the agent is not credible. For $r_{t+1}<Q^{f b}$ the principal would have an incentive to offer a contract that extracts all rents from the agent. Step 3. We prove that the optimal incentive contract features excessive bonuses, $b_{t}^{*}\left(r_{t}\right)>\Delta y$. Under an optimal contract, the principal chooses $w_{t}$ and $b_{t}$ to maximize

$$
\begin{aligned}
V_{t}= & (1-\delta)\left(\underline{y}-w_{t}+f\left(e_{t}\right)\left(\Delta y-b_{t}\right)\right)+\delta\left(1-p\left(s_{t}\right)\right)\left(Q_{t+1}-U_{t+1}(0)\right) \\
& +\delta p\left(s_{t}\right) G\left(Q_{t+1}\right)\left(Q_{t+1}-\mathbb{E}_{G}\left[U_{t+1}\left(r_{r+1}\right) \mid r_{r+1} \leq Q_{t+1}\right]\right),
\end{aligned}
$$

subject to the agent's incentive constraints in (13), (14), and the constraint that the agent earns his equilibrium level of utility, i.e.,

$$
\begin{aligned}
\max _{e_{t}, s_{t}} & (1-\delta)\left(w_{t}+f\left(e_{t}\right) b_{t}-c\left(e_{t}, s_{t}\right)\right)+\delta\left(1-p\left(s_{t}\right)\right) U_{t+1}(0) \\
& +\delta p\left(s_{t}\right) G\left(Q_{t+1}\right) \mathbb{E}_{G}\left[U_{t+1}\left(r_{r+1}\right) \mid r_{r+1} \leq Q_{t+1}\right] \\
& +\delta p\left(s_{t}\right)\left(1-G\left(Q_{t+1}\right)\right) \mathbb{E}_{G}\left[r_{r+1} \mid r_{r+1}>Q_{t+1}\right] \geq U_{t}\left(r_{t}\right) .
\end{aligned}
$$

From the last constraint we get that the principal can substitute fixed wage and bonus at the rate $\frac{d w_{t}}{d b_{t}}=-f\left(e_{t}\right)$. The first-order condition for an optimal bonus is then given by

$$
\begin{aligned}
\frac{\partial V_{t}}{\partial b_{t}}= & \frac{d e_{t}}{d b_{t}}(1-\delta) f^{\prime}\left(e_{t}\right)\left(\Delta y-b_{t}\right) \\
& -\frac{d s_{t}}{d b_{t}} \delta p^{\prime}\left(s_{t}\right)\left[Q_{t+1}-U_{t+1}(0)-G\left(Q_{t+1}\right)\left(Q_{t+1}-\mathbb{E}_{G}\left[U_{t+1}\left(r_{r+1}\right) \mid r_{r+1} \leq Q_{t+1}\right]\right)\right]=0 .
\end{aligned}
$$


Consider the term in the large squared brackets in the second line. Since the principal cannot credibly promise the full joint surplus to the agent, this term is strictly positive. Since we have $\frac{d s_{t}}{d b_{t}}<0$, the principal's profit strictly increases in the bonus at $b_{t}=\Delta y$. The optimal bonus must therefore be excessive.

Proof of Proposition 3. The proof proceeds in steps. Step 1. We derive inequality (17), i.e., a condition under which there exists a payoff floor contract that is an equilibrium contract and that is strictly better for the principal than the $n r$-contract. Denote by $w^{n r}\left(r_{t}\right)$ the wage in period $t$ under the $n r$-contract if the outside option value is $r_{t}$. Consider the following change in $\sigma^{n r}$. The principal reduces the bonus from $b^{n r}$ to $b^{p f}$ and then chooses $\bar{u}$ so that the agent's search effort remains constant, that is, the agent's optimal search effort is $s_{t}=s^{n r}$ provided that $d_{t}=1, b_{t}=b^{p f}$, and his continuation utility is $U_{t+1}\left(r_{t+1}\right)=r_{t+1}$ when $r_{t+1} \geq \bar{u}$ and $U_{t+1}\left(r_{t+1}\right)=\bar{u}$ otherwise. Denote by $e^{p f}$ the agent's work effort given that his search effort is $s^{n r}$ and the bonus is $b^{p f}$. By construction, we have $e^{p f}<e^{n r}$. Let $w^{p f}\left(r_{t}\right)$ be the wage that implements the payoff floor. The wage $w^{n r}\left(r_{t}\right)$ is implicitly defined by

$$
(1-\delta)\left(w^{n r}\left(r_{t}\right)+f\left(e^{n r}\right) b^{n r}-c\left(e^{n r}, s^{n r}\right)\right)+\delta p\left(s^{n r}\right) \mathbb{E}_{G}\left[r_{t+1}\right]=r_{t}
$$

and wage $w^{p f}\left(r_{t}\right)$ is implicitly defined by

$$
\begin{aligned}
& (1-\delta)\left(w^{p f}\left(r_{t}\right)+f\left(e^{p f}\right) b^{p f}-c\left(e^{p f}, s^{n r}\right)\right)+\delta\left(1-p\left(s^{n r}\right)\right) \bar{u} \\
& +\delta p\left(s^{n r}\right) G(\bar{u}) \bar{u}+\delta p\left(s^{n r}\right)(1-G(\bar{u})) \mathbb{E}_{G}\left[r_{t+1} \mid r_{t+1} \geq \bar{u}\right]=\max \left\{r_{t}, \bar{u}\right\} .
\end{aligned}
$$

Note that for $\bar{u}>0$ we have

$$
\left(1-p\left(s^{n r}\right)\right) \bar{u}+p\left(s^{n r}\right) G(\bar{u}) \bar{u}+p\left(s^{n r}\right)(1-G(\bar{u})) \mathbb{E}_{G}\left[r_{t+1} \mid r_{t+1} \geq \bar{u}\right]>p\left(s^{n r}\right) \mathbb{E}_{G}\left[r_{t+1}\right] .
$$

Hence, from equations (36) and (37) we get

$$
w^{p f}\left(r_{t}\right) \leq w^{n r}\left(r_{t}\right)+\frac{1}{1-\delta} \max \left\{\bar{u}-r_{t}, 0\right\}+f\left(e^{p f}\right)\left(b^{n r}-b^{p f}\right)+\int_{e^{p f}}^{e^{n r}}\left[f^{\prime}(e) b^{n r}-c_{e}\left(e, s^{n r}\right)\right] d e
$$

Observe that the third term on the right-hand side is an expected payment that the principal also pays under the $n r$-contract through the bonus. We use this observation to derive a lower bound for the difference between the principal's normalized expected period- $t$ payoff under contract $\sigma^{p f}$ and under contract $\sigma^{n r}$, provided that $d_{t}=1$. The normalized expected period- $t$ payoff for given $r_{t}$ and $d_{t}=1$ equals $(1-\delta)\left(y-w_{t}+f\left(e_{t}\right)\left(\Delta y-b_{t}\right)\right)$. The inequality in (39) 
implies that a possible lower bound is given by

$$
\begin{aligned}
& (1-\delta)\left(f\left(e^{p f}\right)-f\left(e^{n r}\right)\right)\left(\Delta y-b^{n r}\right)-(1-\delta) \int_{e^{p f}}^{e^{n r}}\left[f^{\prime}(e) b^{n r}-c_{e}\left(e, s^{n r}\right)\right] d e \\
& -\left(1-p\left(s^{n r}\right)\right) \bar{u}-p\left(s^{n r}\right) \int_{0}^{\bar{u}} g(r)(\bar{u}-r) d r .
\end{aligned}
$$

Note that the marginal increase in the term $\int_{e^{p f}}^{e^{n r}}\left[f^{\prime}(e) b^{n r}-c_{e}\left(e, s^{n r}\right)\right] d e$ as $b^{p f}$ is reduced starting from $b^{n r}$ equals zero. Using (40) and the fact that $g(0)=0$, we get condition (17). In a period $t$ with $r_{t}=0$, the principal's total expected payoff $V_{t}$ is larger under $\sigma^{p f}$ than under $\sigma^{n r}$ if $b^{p f}$ is close enough to $b^{n r}$ and condition (17) holds at $\sigma^{n r}$. Denote the left-hand side of condition (17) by $\Gamma$. Step 2. We replace $f^{\prime}\left(e_{t}\right)\left(\Delta y-b_{t}\right)$ in $\Gamma$ by an alternative expression, so that in the next step we can examine under what circumstances condition (17) is satisfied. Note that $b^{n r}$ and $w^{n r}\left(r_{t}\right)$ maximize

$$
\begin{aligned}
V_{t}= & (1-\delta)\left(\underline{y}-w_{t}+f\left(e_{t}\right)\left(\Delta y-b_{t}\right)\right) \\
& +\delta\left(1-p\left(s_{t}\right)\right) Q_{t+1}+\delta p\left(s_{t}\right) G\left(Q_{t+1}\right)\left(Q_{t+1}-\mathbb{E}_{G}\left[r_{r+1} \mid r_{r+1} \leq Q_{t+1}\right]\right),
\end{aligned}
$$

subject to the agent's incentive constraints in (13) and (14), as well as the participation constraint

$$
\max _{e_{t}, s_{t}}(1-\delta)\left(w_{t}+f\left(e_{t}\right) b_{t}-c\left(e_{t}, s_{t}\right)\right)+\delta p\left(s_{t}\right) \mathbb{E}_{G}\left[r_{t+1}\right] \geq r_{t}
$$

Since the participation constraint must be binding, we have

$$
(1-\delta) w_{t}=r_{t}+(1-\delta) c\left(e_{t}, s_{t}\right)-(1-\delta) f\left(e_{t}\right) b_{t}-\delta p\left(s_{t}\right) \mathbb{E}_{G}\left[r_{r+1}\right]
$$

at $\sigma^{n r}$. From this equality, we get $\frac{d w_{t}}{d b_{t}}=-f\left(e_{t}\right)$ at $\sigma^{n r}$. Thus, $b^{n r}$ is implicitly defined by

$$
\begin{aligned}
\frac{\partial V_{t}}{\partial b_{t}}= & (1-\delta) f^{\prime}\left(e_{t}\right)\left(\Delta y-b_{t}\right) \frac{d e_{t}}{d b_{t}}-\delta p^{\prime}\left(s_{t}\right)\left(1-G\left(Q_{t+1}\right)\right) Q_{t+1} \frac{d s_{t}}{d b_{t}} \\
& -\delta p^{\prime}\left(s_{t}\right) G\left(Q_{t+1}\right) \mathbb{E}_{G}\left[r_{r+1} \mid r_{r+1} \leq Q_{t+1}\right] \frac{d s_{t}}{d b_{t}}=0
\end{aligned}
$$

at $\sigma^{n r}$. We therefore must have

$$
\left|f^{\prime}\left(e_{t}\right)\left(\Delta y-b_{t}\right)\right| \geq\left|\frac{\delta}{1-\delta} p^{\prime}\left(s_{t}\right) G\left(Q_{t+1}\right) \mathbb{E}_{G}\left[r_{r+1} \mid r_{r+1} \leq Q_{t+1}\right] \frac{d s_{t}}{d b_{t}}\left(\frac{d e_{t}}{d b_{t}}\right)^{-1}\right|
$$


at $\sigma^{n r}$. Thus, condition (17) holds if

$$
\begin{gathered}
\delta p^{\prime}\left(s^{n r}\right) G\left(Q^{n r}\right) \mathbb{E}_{G}\left[r_{r+1} \mid r_{r+1} \leq Q^{n r}\right]+\left(\frac{d s_{t}}{d \bar{u}}\right)^{-1}+\frac{\delta\left[\left(1-p\left(s^{n r}\right)\right)+p\left(s^{n r}\right) G\left(Q^{n r}\right)\right]}{1-\delta\left[\left(1-p\left(s^{n r}\right)\right)+p\left(s^{n r}\right) G\left(Q^{n r}\right)\right]} \\
\times\left[\delta p^{\prime}\left(s^{n r}\right) G\left(Q^{n r}\right) \mathbb{E}_{G}\left[r_{r+1} \mid r_{r+1} \leq Q^{n r}\right]+\left(1-p\left(s^{n r}\right)\right)\left(\frac{d s_{t}}{d \bar{u}}\right)^{-1}\right]>0
\end{gathered}
$$

at $\sigma^{n r}$. Step 3. We show that condition (46) is satisfied for an open set of environments. Assume

$$
c\left(e_{t}, s_{t}\right)=\frac{1}{2} \beta_{1} e_{t}^{2}+\frac{1}{2} \beta_{2} e_{t}^{2} s_{t}^{2}+\frac{1}{2} \beta_{3} s_{t}^{2},
$$

$f\left(e_{t}\right)=f^{\prime} e_{t}, p\left(s_{t}\right)=p^{\prime} s_{t}$, and $\bar{e}=\bar{s}=1$. From these parametric assumptions, we get

$$
\left|\frac{d s_{t}}{d \bar{u}}\right|>\left|-\frac{\delta}{1-\delta} \frac{p^{\prime}}{c_{s s}\left(e_{t}, s_{t}\right)}\right|
$$

at $\sigma^{n r}$. Consider the term in the large squared brackets in the second line of (46). Using the inequality in (48), we get that this term is strictly positive in the example if

$$
\frac{\delta^{2}}{1-\delta} \frac{\left(p^{\prime}\right)^{2}}{c_{s s}\left(e_{t}, s_{t}\right)} G\left(Q^{n r}\right) \mathbb{E}_{G}\left[r_{t+1} \mid r_{t+1} \leq Q^{n r}\right]>1-p\left(s^{n r}\right)
$$

at $\sigma^{n r}$. We now show in several steps that the left-hand side of this inequality can be much larger than the right-hand side. First, consider the cost term $c_{s s}\left(e_{t}, s_{t}\right)$. It must be large enough so that search effort is given by an interior solution. From the first-order condition (14), which characterizes optimal search, we get that

$$
s_{t} \in\left(\frac{\delta}{1-\delta} \frac{1}{\beta_{2}+\beta_{3}} p^{\prime} \mathbb{E}_{G}\left[r_{t+1}\right], \frac{\delta}{1-\delta} \frac{1}{\beta_{3}} p^{\prime} \mathbb{E}_{G}\left[r_{t+1}\right]\right)
$$

at $\sigma^{n r}$. To ensure that $s_{t}<\bar{s}$, we choose some $\beta_{3} \approx \frac{\delta}{1-\delta} p^{\prime} \mathbb{E}_{G}\left[r_{t+1}\right]$. Note that $c_{s s}\left(e_{t}, s_{t}\right) \leq \beta_{2}+\beta_{3}$ in the example. Next, consider the terms $G\left(Q^{n r}\right)$ and $\mathbb{E}_{G}\left[r_{t+1} \mid r_{t+1} \leq Q^{n r}\right]$. Recall that

$$
\begin{aligned}
Q^{n r}= & (1-\delta)\left[\underline{y}+f\left(e^{n r}\right) \Delta y-c\left(e^{n r}, s^{n r}\right)\right]+\delta\left(1-p\left(s^{n r}\right)\right) Q^{n r} \\
& +\delta p\left(s^{n r}\right) G\left(Q^{n r}\right) Q^{n r}+\delta p\left(s^{n r}\right)\left(1-G\left(Q^{n r}\right)\right) \mathbb{E}_{G}\left[r_{t+1} \mid r_{t+1} \geq Q^{n r}\right] .
\end{aligned}
$$

Since $e^{n r}$ and $s^{n r}$ do not depend on $\underline{y}, Q^{n r}$ strictly increases in $\underline{y}$. Hence, we can find $\underline{y}$ and a distribution $G$ that puts most probability mass on small realizations of $r_{t}$ so that $G\left(Q^{n r}\right)$ is close to 1 and $\mathbb{E}_{G}\left[r_{t+1} \mid r_{t+1} \leq Q^{n r}\right] \approx \mathbb{E}_{G}\left[r_{t+1}\right]$. Finally, consider the term $1-p\left(s^{n r}\right)$. Given that $\beta_{3} \approx \frac{\delta}{1-\delta} p^{\prime} \mathbb{E}_{G}\left[r_{t+1}\right]$, this term is close to zero if $p^{\prime}$ is close to 1 and $\beta_{2}$ is small relative to $\beta_{3}$. So we can find parameters such that at $\sigma^{n r}$ the left-hand side of (49) is close to 1 , the right-hand 
side is close to $0, \delta \approx 1$, and $G\left(Q^{n r}\right) \approx 1$, so that overall $\Gamma<0$. Step 4. We now can show that under an optimal incentive contract we must have $U_{t}^{*}\left(r_{t}\right)>r_{t}$ for any $t>1$ with $d_{t}=1$ and for some set of values $r_{t}$ that has positive measure. Note that the best equilibrium contract under which the principal extracts all rents from the agent in all periods is the $n r$-contract. If condition (17) is satisfied, there exists a payoff floor contract $\sigma^{\bar{u}}$ with $\bar{u}>0$ which is an equilibrium contract and that is strictly better for the principal than the $n r$-contract.

Proof of Proposition 4. Assume by contradiction that there is an incentive contract $\sigma$ that is strictly better for the principal than the optimal payoff floor contract $\sigma^{\bar{u}^{*}}$. By Lemma 1, we can focus w.l.o.g. on incentive contracts $\sigma$ in which the agent's total expected utility $U_{t}$ only depends on his outside option value $r_{t}$. Then under $\sigma$ there exists an interval $\left(r_{L}, r_{H}\right) \subset(0, \infty)$ and a period $t$ such that $U_{t+1}\left(r_{t+1}\right)>\max \left\{U_{t+1}(0), r_{t+1}\right\}$ for all $r_{t+1} \in\left(r_{L}, r_{H}\right) .{ }^{19}$ Select such an interval so that reducing $U_{t+1}\left(r_{t+1}\right)$ to $\max \left\{U_{t+1}(0), r_{t+1}\right\}$ for all $r_{t+1} \in\left(r_{L}, r_{H}\right)$ would not violate the constraint that $U_{t+1}\left(r_{t+1}\right)$ must be weakly increasing in $r_{t+1}$. Denote by $w_{t}\left(r_{t}\right)$ the agent's wage and by $b_{t}\left(r_{t}\right)$ the agent's bonus on the equilibrium path in period $t$ under $\sigma$ if his outside option is $r_{t}$. Denote by $e_{t}\left(r_{t}\right)$ and $s_{t}\left(r_{t}\right)$ the corresponding effort levels. By Proposition 2, the bonus must be excessive, $b_{t}\left(r_{t}\right)>\Delta y$. To show that $\sigma$ is not optimal for the principal, we construct an alternative contract $\hat{\sigma}$ that is strictly better for the principal. Define $w_{t+1}^{[1]}\left(r_{t+1}\right)=$ $w_{t+1}\left(r_{t+1}\right)$ for all $r_{t+1} \in[0, \infty] \backslash\left(r_{L}, r_{H}\right)$ and

$$
w_{t+1}^{[1]}\left(r_{t+1}\right)=w_{t+1}\left(r_{t+1}\right)-\frac{1}{1-\delta}\left[U_{t+1}\left(r_{t+1}\right)-\max \left\{U_{t+1}(0), r_{t+1}\right\}\right]
$$

for all $r_{t+1} \in\left(r_{L}, r_{H}\right)$. Next, define

$$
w_{t}^{[1]}\left(r_{t}\right)=w_{t}\left(r_{t}\right)+p\left(s_{t}\left(r_{t}\right)\right) \frac{\delta}{1-\delta} \int_{r_{L}}^{r_{H}}\left[U_{t+1}\left(r_{t+1}\right)-\max \left\{U_{t+1}(0), r_{t+1}\right\}\right] g\left(r_{t+1}\right) d r_{t+1} .
$$

Note that if we keep $e_{t}\left(r_{t}\right)$ and $s_{t}\left(r_{t}\right)$ fixed, the period- $t$ payoff of each party remains the same when, on the equilibrium path of $\sigma$, we replace $w_{t}\left(r_{t}\right)$ by $w_{t}^{[1]}\left(r_{t}\right)$ and $w_{t+1}\left(r_{t+1}\right)$ by $w_{t+1}^{[1]}\left(r_{t+1}\right)$. In equilibrium, the agent's search effort is implicitly defined by

$$
\frac{\delta}{1-\delta} p^{\prime}\left(s_{t}\left(r_{t}\right)\right) \int_{0}^{\infty} U_{t+1}\left(r_{t+1}\right) g\left(r_{t+1}\right) d r_{t+1}=c_{s}\left(e_{t}\left(r_{t}\right), s_{t}\left(r_{t}\right)\right) \text {. }
$$

Hence, under the new wages, search incentives in period $t$ are smaller. Let $\sigma^{[1]}$ be identical to $\sigma$ except that on the equilibrium path the wage in period $t$ is given by $w_{t}^{[1]}\left(r_{t}\right)$, the wage in period $t+1$ is given by $w_{t+1}^{[1]}\left(r_{t+1}\right)$, and the bonus $b_{t}^{[1]}\left(r_{t}\right)$ is chosen so that the agent's search effort in period $t$ is the same as under $\sigma$ when $d_{t}=1$. By construction, we have $\Delta y<b_{t}^{[1]}\left(r_{t}\right)<b_{t}\left(r_{t}\right)$

\footnotetext{
${ }^{19}$ Here we use the statement from footnote 11.
} 
for all $r_{t}$ that imply $d_{t}=1$ and therefore smaller work effort in period $t$ under $\sigma^{[1]}$ than under $\sigma$ when $d_{t}=1$. Denote by $e_{t}^{[1]}\left(r_{t}\right)$ the search effort in period $t$ under $\sigma^{[1]}$ when $d_{t}=1$. To compensate the agent for the lower bonus, we choose

$$
w_{t}^{[2]}\left(r_{t}\right)=w_{t}^{[1]}\left(r_{t}\right)+\int_{0}^{e^{[1]}\left(r_{t}\right)} f^{\prime}(e)\left[b_{t}\left(r_{t}\right)-b_{t}^{[1]}\left(r_{t}\right)\right] d e+\int_{e^{[1]}\left(r_{t}\right)}^{e_{t}\left(r_{t}\right)}\left[f^{\prime}(e) b_{t}\left(r_{t}\right)-c_{e}\left(e, s_{t}\left(r_{t}\right)\right)\right] d e
$$

Let $\sigma^{[2]}$ be identical to $\sigma^{[1]}$ except that the wage in period $t$ on the equilibrium path is given by $w_{t}^{[2]}\left(r_{t}\right)$ instead of $w_{t}^{[1]}\left(r_{t}\right)$. The inequality $\Delta y<b_{t}^{[1]}\left(r_{t}\right)<b_{t}\left(r_{t}\right)$ implies that $\frac{\partial Q_{t}}{\partial e_{t}}<0$ at all effort levels $e \in\left[e_{t}^{[1]}\left(r_{t}\right), e_{t}\left(r_{t}\right)\right]$. Hence, given that $d_{t}=1$, we have for any $r_{t}$ that

$$
V_{t}^{[2]}\left(r_{t}\right)=Q_{t}^{[2]}\left(r_{t}\right)-U_{t}^{[2]}\left(r_{t}\right)=Q_{t}^{[2]}\left(r_{t}\right)-U_{t}\left(r_{t}\right)>Q_{t}\left(r_{t}\right)-U_{t}\left(r_{t}\right)=V_{t}\left(r_{t}\right)
$$

which completes the contradiction.

Proof of Proposition 5. We first examine under what conditions the inequality in (18) holds. As in Step 2 of the proof of Proposition 3 we get that $b^{n r}$ is implicitly defined by the first-order condition in (44), so that

$$
f^{\prime}\left(e_{t}\right)\left(\Delta y-b^{n r}\right)=\frac{\delta}{1-\delta} p^{\prime}\left(s_{t}\right)\left[\left(1-G\left(Q^{n r}\right)\right) Q^{n r}+G\left(Q^{n r}\right) \mathbb{E}_{G}\left[r_{r+1} \mid r_{r+1} \leq Q^{n r}\right]\right] \frac{d s_{t}}{d b_{t}}\left(\frac{d e_{t}}{d b_{t}}\right)^{-1}
$$

at $\sigma^{n r}$. Consider the limit case with $\mathbb{E}_{G}\left[r_{r+1} \mid r_{r+1} \leq Q^{n r}\right]=\mathbb{E}_{G}\left[r_{r+1}\right]$. In this case, we have $G\left(Q^{n r}\right)=1$, so that

$$
b^{n r}=\Delta y+\frac{1}{1-\delta} \frac{p^{\prime}\left(s^{n r}\right)}{f^{\prime}\left(e^{n r}\right)} \mathbb{E}_{G}\left[r_{r+1}\right] \frac{c_{e s}\left(e^{n r}, s^{n r}\right)}{c_{s s}\left(e^{n r}, s^{n r}\right)} .
$$

In the limit case, the bonus $b^{n r}$ and wage $w^{n r}\left(r_{t}\right)$ maximize

$$
V_{t}\left(r_{t}\right)=(1-\delta)\left(\underline{y}+f\left(e_{t}\right)\left(\Delta y-b_{t}\right)-w_{t}\left(r_{t}\right)\right)+\delta\left[\underline{y}+f\left(e_{t}\right) \Delta y-c\left(e_{t}, s_{t}\right)-p\left(s_{t}\right) \mathbb{E}_{G}\left[r_{t+1}\right]\right],
$$

subject to the agent's incentive constraints in (13) and (14), as well as the participation constraint

$$
\max _{e_{t}, s_{t}}(1-\delta)\left(w_{t}\left(r_{t}\right)+f\left(e_{t}\right) b_{t}-c\left(e_{t}, s_{t}\right)\right)+\delta p\left(s_{t}\right) \mathbb{E}_{G}\left[r_{t+1}\right] \geq r_{t} .
$$

The participation constraint implies

$$
w_{t}\left(r_{t}\right)=c\left(e_{t}, s_{t}\right)-f\left(e_{t}\right) b_{t}+\frac{1}{1-\delta}\left(r_{t}-\delta p\left(s_{t}\right) \mathbb{E}_{G}\left[r_{t+1}\right]\right) .
$$

We plug this back into (59) and see that $b^{n r}$ maximizes $f\left(e_{t}\right) \Delta y-c\left(e_{t}, s_{t}\right)$. Hence, we have

$$
f\left(e^{n r}\right) \Delta y-c\left(e^{n r}, s^{n r}\right)>f(0) \Delta y-c\left(0, s^{z}\right)=-c\left(0, s^{z}\right)
$$


In the limit case, condition (18) is implied by

$$
-(1-\delta) b^{n r}+\delta Q^{n r}>\delta Q^{z}
$$

where $Q^{n r}=\underline{y}+f\left(e^{n r}\right) \Delta y-c\left(e^{n r}, s^{n r}\right)$ and $Q^{z} \leq \underline{y}+f(0) \Delta y-c\left(0, s^{z}\right)$. Hence, the inequality in (63) is satisfied if $(1-\delta) b^{n r}$ is sufficiently small. By (58) we have $(1-\delta) b^{n r} \rightarrow 0$ for $\delta \rightarrow 1$ and $\mathbb{E}_{G}\left[r_{t+1}\right] \frac{c_{e s}\left(e^{n r}, s^{n r}\right)}{c_{s s}\left(e^{n r}, s^{n r}\right)} \rightarrow 0$. Note that in our example in (47), we have $\mathbb{E}_{G}\left[r_{t+1}\right] \frac{c_{e s}\left(e^{n r}, s^{n r}\right)}{c_{s s}\left(e^{n r}, s^{n r}\right)} \rightarrow 0$ for $\frac{\beta_{2}}{\beta_{3}} \rightarrow 0$. The first statement in the proposition then follows from the fact that the principal's and the agent's payoff under the two contracts $\sigma^{n r}$ and $\sigma^{z}$ moves continuously in the distribution $G$ and the search function $p$. Statements (a) and (b) can be shown as in the proofs of Propositions 2 and 3 using the fact that both (17) and (63) can simultaneously be satisfied.

Proof of Proposition 6. The proof proceeds in steps. Step 1. We show that for large outside option values $r_{t}$ that imply $d_{t}=1$ the optimal contract features an excessive bonus, $b^{l l}\left(r_{t}\right)>\Delta y$. Note that $Q_{t}^{\max }$ strictly increases in $\underline{y}$. Consider the participation constraint in (20). The agent's total utility strictly increases in $w_{t}$ and $b_{t}$. Suppose that $b_{t}^{l l}\left(r_{t}\right) \leq \Delta y$ for all $r_{t} \in\left[0, Q_{t}^{\max }\right]$. If $\underline{y}$ is large enough, then for sufficiently large outside option values $r_{t} \leq Q_{t}^{\max }$ we must have $w_{t}^{l l}\left(r_{t}\right)>\Delta y$. We then can offer a bonus of $\hat{b}_{t}^{l l}\left(r_{t}\right)=\Delta y$ and adjust $w_{t}^{l l}\left(r_{t}\right)$ to $\hat{w}_{t}^{l l}\left(r_{t}\right)$ so that the agent's total utility remains at $U_{t}^{l l}\left(r_{t}\right)$. Since $w_{t}^{l l}\left(r_{t}\right)>\Delta y$ we must have $\hat{w}_{t}^{l l}\left(r_{t}\right)>0$. Thus, we can further increase $\hat{b}_{t}^{l l}\left(r_{t}\right)$ while keeping the agent's total utility constant. As discussed in Section 4 , this change generates first-order gains, but only second-order costs for the principal. Thus, the optimal bonus must be excessive. Step 2. We show that the optimal contract features a payoff floor. Suppose that $r_{t}=0$ and assume by contradiction that $U_{t}^{l l}(0)=0$. Consider the participation constraint in (20). By limited liability, we have $U_{t+1}^{l l}\left(r_{t+1}\right)>0$ for all $r_{t+1}$ so that the participation is satisfied for all contracts $\left(w_{t}, b_{t}\right)$ with $w_{t} \geq 0$ and $w_{t}+b_{t} \geq 0$. Thus, the optimal wage in period $t$ is $w_{t}=0$ and the principal's objective function becomes

$$
\begin{aligned}
\max _{b_{t} \geq 0} & (1-\delta)\left(\underline{y}+f\left(e_{t}\right)\left(\Delta y-b_{t}\right)\right)+\delta\left(1-p\left(s_{t}\right)\right)\left(Q_{t+1}^{l l}(0)-U_{t+1}(0)\right) \\
& +\delta p\left(s_{t}\right) G\left(Q_{t+1}^{\max }\right) \mathbb{E}_{G}\left[Q_{t+1}^{l l}\left(r_{t+1}\right)-U_{t+1}^{l l}\left(r_{r+1}\right) \mid r_{t+1} \leq Q_{t+1}^{\max }\right]
\end{aligned}
$$

Since in period $t$ the principal can influence $Q_{t}^{l l}\left(r_{t}\right)$ only through the bonus $b_{t}\left(r_{t}\right)$ (provided that the agent's expectations are fixed), $Q_{t+1}^{l l}\left(r_{t+1}\right)-U_{t+1}^{l l}\left(r_{r+1}\right)$ cannot be increasing in $r_{r+1}$. Moreover, $Q_{t+1}^{l l}\left(r_{t+1}\right)-U_{t+1}^{l l}\left(r_{r+1}\right)$ must be decreasing for some value of $r_{t+1} \leq Q_{t+1}^{\max }$; otherwise, the principal's payoff would always be zero. The first-order condition for the optimal bonus in 
period $t$ is

$$
\begin{aligned}
\frac{\partial V_{t}}{\partial b_{t}}= & (1-\delta) f^{\prime}\left(e_{t}\right)\left(\Delta y-b_{t}\right) \frac{d e_{t}}{d b_{t}}-(1-\delta) f\left(e_{t}\right)-\delta p^{\prime}\left(s_{t}\right)\left(Q_{t+1}^{l l}(0)-U_{t+1}^{l l}(0)\right) \frac{d s_{t}}{d b_{t}} \\
& +\delta p^{\prime}\left(s_{t}\right) \mathbb{E}_{G}\left[Q_{t+1}^{l l}\left(r_{t+1}\right)-U_{t+1}^{l l}\left(r_{r+1}\right) \mid r_{t+1} \leq Q_{t+1}^{m a x}\right] \frac{d s_{t}}{d b_{t}}=0 .
\end{aligned}
$$

At $b_{t}=0$ we have $e_{t}=0$ so that the left-hand side is strictly positive. Thus, the optimal bonus is positive. The result then follows from the free disposal assumption. 